\section{CONCILIACIÓN O REVOLUCIÓN: LOS CAMINOS ENFRENTADOS DEL LIBERALISMO PENINSULAR (PORTUGAL Y ESPAÑA, 1863-1866)}

\author{
Ignacio Chato Gonzalo \\ Profesor del I.E.S. "Jaranda" (Jarandilla de la Vera) \\ Ignacio.chato.g@gmail.es
}

\section{RECONCILIATION OR REVOLUTION: THE TWO PATHS OF LIBERALISM ON THE IBERIAN PENINSULA (PORTUGAL AND SPAIN, 1863-1866)}

Cómo citar este artículo/Citation: Chato Gonzalo, I. (2014). "Conciliación o revolución: los caminos enfrentados del liberalismo peninsular (Portugal y España, 1863-1866)". Arbor, 190 (766): a111. doi: http://dx.doi.org/10.3989/ arbor.2014.766n2003

Recibido: 11 septiembre 2012. Aceptado: 31 diciembre 2013.
Copyright: (c) 2014 CSIC. Este es un artículo de acceso abierto distribuido bajo los términos de la licencia Creative Commons Attribution-Non Commercial (by-nc) Spain 3.0.
RESUMEN: Las propuestas conciliatorias que se llevaron a cabo desde mediados del siglo XIX en la península ibérica marcaron, en función de sus experiencias y resultados, un itinerario dispar en el devenir de los regímenes liberales de España y Portugal. El triunfo de la Regeneração, aunque supuso una indudable tranquilidad política y constitucional, provocó la alteración de la dinámica política y la gestación y desarrollo de nuevos partidos. La formulación de estas nuevas identidades y el emerger del radicalismo, que representó un especial protagonismo, iba a determinar el nacimiento de un ciclo político no exento de tensiones y dificultades, ensayándose nuevas apuestas conciliatorias con las que asegurar la estabilidad del régimen y limitar toda expectativa de revolución. En cuanto a España, truncada la tentativa de conciliación llevada a cabo durante el gobierno largo de O'Donnell, el funcionamiento político retomó, a pesar del clima liberalizador que pareció establecerse, las mimas inercias y deficiencias que había arrastrado en las décadas anteriores, lo que llevó al retraimiento de los progresistas y a su apuesta por la vía revolucionaria. Con la revolución en el horizonte, se venían a expresar los límites y alcances de un régimen que, incapaz de aunar a las principales fuerzas políticas dentro de un mismo marco político, daba ya muestras de su crisis y agotamiento.

PALABRAS CLAVE: Conciliación; revolución; sistema de partidos; unionismo; "fusionismo".
ABSTRACT: Since the second half of the 19th century polices of reconciliation on the Iberian peninsula have moved along two opposite paths as the Spanish and Portuguese liberal regimes developed in different directions according to their different experiences and achievements. Although the success of the Regeneração undoubtedly meant political and constitutional stability, it also caused a deep shift in the political dynamics and triggered the emergence of new parties. In Portugal, the design of these new political identities and the birth of an especially prominent radicalism marked the beginning of a new era rife with tensions and difficulties where attempts at reconciliation sought to guarantee the regime's stability while stifling expectations of revolution. In Spain, despite the new liberal atmosphere, after the failure of O'Donnell's attempts at reconciliation during his so called "Iong government", the political structure remained beset by the same inertias and defects as in the previous decades, discouraging the progressives and driving them towards a pro-revolutionary stance. The threat of a future revolution exposed the limits of an exhausted regime, unable to unite the main political parties within a single political system.

KEYWORDS: Politics of conciliation; revolution; party system; "unionismo"; "fusionismo". 


\section{REGENERACIÓN POLÍTICA Y RENOVACIÓN DE LOS SISTEMAS DE PARTIDOS PENINSULARES}

A pesar de los aparentes paralelismos y similitudes, las trayectorias políticas de España y Portugal han marcado notables disimetrías. En el caso peninsular, ni la vecindad y la mutua influencia, ni la vivencia coetánea de determinadas experiencias históricas, ni siquiera la afinidad de corrientes y tendencias políticas, deben difuminar las singularidades del devenir político de ambos países. Y si este criterio debe tenerse en cuenta ya en la primera mitad del siglo XIX, mayor aún es la divergencia a partir de 1851, a raíz del proceso histórico que dio nacimiento en Portugal el nuevo régimen de la Regeneração. Fue precisamente desde esa coyuntura histórica cuando los derroteros de los sistemas liberales de uno y otro país trazaron rumbos bien diferenciados, definiendo, en gran medida, la particular evolución política de uno y otro país hasta bien entrado el siglo $X^{1}$. Aunque resulte innecesario justificar la pertinencia de los estudios comparados, conviene destacar el potencial renovador que, en el ámbito de la historia política, puede aportarnos el análisis conjunto de las dinámicas políticas seguidas en ambos países.

La elección de este particular marco temporal, desde inicios de la década de los cincuenta hasta el tercer cuarto del siglo XIX, que puede parecer escasamente significativo, permite sacar a la luz procesos que han pasado desapercibidos, observando desde un nuevo prisma experiencias que ayudan a repensar la dinámica del régimen liberal. Es el caso de las que hemos venido a denominar "estrategias de conciliación", que supusieron una nueva vía dentro del sistema de partidos, dando nacimiento a objetivos, dinámicas y proyectos políticos alternativos. Una reconsideración de determinadas posturas políticas y partidistas que, enajenándose de la inercia de la confrontación y del círculo de la violencia, planteaba nuevos espacios para el acuerdo, la unión y el pacto. Se trataba de abrir vías de entendimiento para salir del círculo vicioso al que había conducido la concepción exclusivista del poder y la ineludible tendencia a excluir al adversario. Solo así se pueden analizar de una forma más cabal y correcta los postulados del puritanismo español, o las experiencias llevadas a cabo posteriormente por la Unión Liberal, y emparentarlas con el proyecto regenerador portugués, que consiguió con más acierto y consentimiento consolidar sus principios en la cultura política del país. Más allá del predominio de la línea interpretativa que impusieron moderados y progresistas, además de los demócratas y los propios carlistas, que descalificaron estas alteraciones del juego político y del funcionamiento del sistema de partidos, es necesario poner en valor las experiencias conciliatorias del unionismo. De este modo podremos ir trenzando la frágil cuerda que, en la evolución política española y peninsular, se extiende por los difíciles derroteros del acuerdo y del consenso.

La década de los cincuenta, como hemos mencionado, marcó un punto de inflexión en la evolución de los regímenes liberales de España y Portugal. El deseo de superar la etapa caracterizadamente revolucionaria que hasta entonces se había prolongado, condujo a la puesta en práctica de nuevas estrategias tendentes a la regeneración política y a la renovación del sistema de partidos. Se buscaba alcanzar la anhelada estabilidad constitucional por medio de la minoración de los maximalismos de partido, una pretendida desideologización de las fuerzas políticas que, a cambio de la asunción de unas bases constitucionales comunes, creían compensar con la modernización del país, las mejoras materiales, el correcto funcionamiento del parlamentarismo y la estabilidad política². Eliminado el uso de medios extrapolíticos para acceder al poder y retirado el ejército del escenario político, la corona podría cumplir sin presiones sus prerrogativas, facilitando el juego de los partidos y consolidando un sistema de alternancia pacífica en el gobierno. Pero para alcanzar este propósito se hacía indispensable transformar sustancialmente las relaciones entre los partidos mayoritarios existentes (cartistas y setembristas en Portugal, moderados y progresistas en España), por medio de lo que vinieron a denominar conciliación política. Un proceso convergente que, a través de la mesura doctrinal y el acercamiento de sus fundamentos políticos, tendía, consciente o inconscientemente, a la transmutación de los partidos históricos y, llegado el caso, a su disolución. Fue en ese contexto en el que vinieron a reformularse cuestiones principales acerca de los partidos políticos, de la situación crítica que atravesaban, del número de fuerzas contendientes que debía albergar el sistema y aun sobre su naturaleza y la necesidad -o no- de su existencia ${ }^{3}$.

Las estrategias conciliatorias que se aplicaron en uno y otro país vinieron a coincidir no solo en su formulación semántica -fusionismo en Portugal y unionismo en España-, sino en la pretensión de trastocar, al menos temporalmente, la dualidad existente en el sistema de partidos. En sustitución de la confrontación política proyectaron establecer un marco de relaciones basado en la formación de entidades interpartidarias o suprapartidarias, sustentado en la 
tolerancia política y en la disolución de los límites y fronteras existentes entre los partidos históricos. Por medio de la formación de coaliciones parlamentarias y gubernamentales, que los ministerios históricos de Loulé ejemplificaron con la presencia del avilismo, o que los "resellados" creyeron efectuar con su participación en la unión liberal, se daba una imagen, no del todo falsa, de superación de las anteriores luchas partidistas. Mientras en Portugal se lograba crear con notable éxito una cultura política compartida, que obligaba a reformular los agrupamientos políticos los nuevos partidos histórico y regenerador definían un nuevo escenario partidario, basado antes en coincidencias y elusiones que en divergencias claramente definidas-, en España la unión liberal no alcanzaba a convertirse en el partido único que ideaba. Incapaz de superponerse a moderados y progresistas, celosos estos de sus respectivas identidades políticas, terminaba convirtiéndose en un partido más en la pugna política, dando por truncado su proyecto unionista ${ }^{4}$.

Lo cierto es que a la altura de 1863 , terminado el gobierno largo de O’Donnell, el legado de la unión liberal resultaba discutible. Aunque era reconocible un largo periodo de estabilidad y de calma política, destacando la actividad parlamentaria desarrollada en ese quinquenio, el sistema de partidos mantenía los mismos desajustes e inconsistencias de hacía una década. La corona, único mecanismo de cambio de gobierno, y los grupos de poder que la tutelaban -esencialmente las diversas fracciones compuestas por las elites moderadas-, seguían constriñendo la dinámica parlamentaria, ajena al juego de los partidos e impermeable a la opinión pública y sus reflejos electorales ${ }^{5}$. Tampoco en Portugal, a pesar del transformismo político operado entre setembristas y cartistas, las migraciones de personajes políticos de uno y otro partido y las uniones "pasteleiras", surgidas al socaire de los nuevos postulados regeneradores, la dinámica parlamentaria recibía los efectos salvíficos de la supuesta modernización política orquestada. La estrategia de unionistas y regeneradores se había dirigido hacia la disolución de los partidos preexistentes, que consideraban moribundos y prescindibles, siendo sustituidos, transitoriamente, por otro tipo de instancias políticas superpuestas que los integraran. Pero ni en España ni en Portugal -en este país tras doce años y la formación de cuatro ministerios (dos regeneradores y dos históricos)- se habían dado los pasos, las intenciones siquiera, de establecer un sistema de alternancia política. Es más, en ambos casos no se contemplaba como deseable, a corto plazo al menos, la configuración de un nuevo sistema de partidos dual. Las amalgamas y conciliaciones políticas y el debilitamiento de los partidos históricos parecían preferibles a la repetición de un bipartidismo, a todas luces imperfecto, que, durante los años de instauración del régimen liberal, había impedido la alternancia y dirigido al país al círculo cerrado de la revolución y la reacción.

Así pues, a la altura de 1863, cerrados ya los períodos en que vinieron a aplicarse las estrategias conciliatorias -desde 1851 en el caso de Portugal y desde 1854 en el de España-, ni en uno ni en otro país se había conseguido establecer un sistema de partidos claramente dual, en el que dos partidos mayoritarios se alternaran pacíficamente en el gobierno, bajo el arbitraje de la corona y al son que marcara la acción del ministerio, la situación de los partidos en el parlamento y los ecos de la opinión pública. En España, además de los dos partidos históricos que habían resistido los embates disolventes del unionismo, la unión liberal se conformaba como un tercer partido en la pugna política, a los que se sumaban, en las fronteras de la legalidad, demócratas y carlistas, ejerciendo un efecto gravitatorio irresistible sobre progresistas y moderados respectivamente. En Portugal, a pesar del transformismo operado entre los antiguos setembristas y cartistas -a excepción de los setembristas que nunca dejaron de ser radicales y de aquellos cartistas recalcitrantes que nunca dejaron de ser conservadores-, aquéllos transmutados en el partido histórico y estos con una presencia exigua y testimonial, los nuevos partidos no alcanzaban a situarse sólidamente en la escena política. El recurso a las coaliciones electorales y de gobierno, más allá de las inercias fusionistas que pudieran representar, resultaba antes un síntoma de la debilidad e inconsistencia de históricos y regeneradores, incapaces de articular un sistema que viniera a tomar forma en torno a ellos. De hecho, el radicalismo, con un protagonismo político inusitado, sin disponer de un espacio de representación propio y solapado a los históricos, constituía un tercer polo en el entramado de los partidos, dificultando el asentamiento próximo de un sistema bipartidista.

\section{EL FRACASO DEL PROYECTO CONCILIATORIO DEL UNIONISMO ESPAÑOL.}

En marzo de 1863, tras casi cinco años ininterrumpidos de gobierno, daba fin la experiencia unionista liderada por O'Donnell, sin haber alcanzado sus proyectos políticos -la formación de un "partido nacional" que sustituyera y englobara a moderados y progresistasy frustrando las expectativas reformistas de los principales hombres políticos que habían dado cuerpo y 
solidez a la unión liberal ${ }^{6}$. La llegada al gobierno del marqués de Miraflores, tras la crisis ministerial que le precedió 7 , marcaba el punto final del unionismo, iniciándose una nueva dinámica política tendente <<a la reconstrucción de los dos partidos históricos ya semidisueltos, confundidos y perturbados a la sazón $>>^{8}$. Una salida que acogían con agrado tanto los progresistas puros como los moderados históricos, en cuanto recompensaba su actitud resistente y eliminaba, al parecer definitivamente, los ataques diluyentes que consideraban causa, y no efecto, de las crisis que padecían. Como reconocía Rivero, <<nunca mueren los partidos, porque hay ciertas ideas fundamentales, ciertas ideas dialécticas en la vida de los pueblos, que nunca perecen, y estas se representan por los partidos, que varían en su forma, pero en la esencia no $>^{9}$. $Y$ es que, frente a la idea de que los partidos históricos habían dejado de tener lugar en la escena política, defendida por la unión liberal, postulando su desaparición, aquéllos defendían su ineludible e inevitable vigencia: <<Los partidos en mi concepto viven siempre cuando son tales partidos -[clamaba González Bravo]-. Los intereses que representan existen siempre; puede desaparecer un partido; puede marchar con el tiempo para adaptarse a las nuevas circunstancias; puede perder su disciplina; puede perder una parte de la organización que tiene; pueden separarse de él algunos hombres que le representaban; pero los partidos nunca mueren, porque o no son partidos, o representan cosas que no perecen jamás en la sociedad $\gg>^{10}$. Una forma de justificar la pervivencia de un partido, el moderado, cuyo estado de fragmentación impedía considerarlo con la suficiente solidez como para garantizar una mínima estabilidad política y mantenerse en el poder. Además del grupo atemperado y liberalizador capitaneado por González Bravo -líder de la minoría moderada durante los gobiernos unionistas-, orquestado en torno a "El Contemporáneo", podían identificarse de centro a derecha del conservadurismo, sin contar con el propio marqués de Miraflores, carente de significación partidaria, con las fracciones de Mon, Narváez -incapaz de aglutinar, como antes, tan dispares intereses y sensibilidades- y Nocedal. Este último, junto al marqués de Orovio, había comandado el núcleo neocatólico, que en los últimos años había ejercido la mayor influencia dentro de un partido que, falto de cohesión y de liderazgo, se había ido extremando en respuesta a los gobiernos disolventes y permisivos de la unión liberal ${ }^{11}$.

Desde la década que lleva su nombre, el moderantismo no había sido capaz de prescindir de la que vino a definirse como "política de resistencia"12. Una postura reactiva frente a los accesos revolucionarios, que difícilmente podía justificarse y mantenerse en la nueva era conciliatoria patrocinada por la unión liberal. Ni siquiera los sucesos de Loja, que esgrimieron como prueba de nuevos y más inquietantes movimientos insurreccionales, permitían legitimar la deriva reaccionaria en la que venía a sumirse el partido moderado. La crisis política surgida a raíz del fracaso del proyecto unionista, había dejado al descubierto la incapacidad del partido moderado de reafirmar su credo político sobre otras bases más liberales y contemporizadoras, recurriendo a sus fuentes doctrinales tradicionales, parapetadas tras la ineluctable figura de Narváez. Se truncaba así el proceso modernizador que, desde dentro del partido, habían iniciado González Bravo y otros personajes reunidos en torno a "El Contemporáneo", diario dirigido por José Luis Albareda. Tal y como Calvo Asensio vendría a denunciar en el congreso: <<no podíamos creer, repito, que la bandera allí levantada y que era la que iba a seguir el nuevo partido moderado, fuese a empuñarla el general Narváez, haciendo con esto responsables y solidarios de su historia a todos los que denodadamente se lanzaban a esa reorganización; no podíamos creer, digo, que por la ley de la necesidad, ciertas personas que han venido trabajando dentro del parlamento para trazar la nueva senda de ese partido, se prestasen, no solo a formar parte del gabinete del general Narváez, sino a querer rehabilitar su nombre, como cabeza o jefe de esta nueva organización $>>^{13}$. El líder progresista avisaba de la postura que, en su propia defensa, vendría a adoptar el progresismo en el caso de que los moderados vinieran a seguir esta nueva línea de conducta, apartada del clima de tolerancia y apertura política que habían asumido, en los últimos años, todos los partidos ${ }^{14}$.

Porque, en efecto, los progresistas puros habían conformado, tanto en las cortes como en la opinión pública -y muy especialmente en su órgano de expresión, "La Iberia"-, una imagen atemperada de sí mismos. Los elementos más sensibles de su ideario político, desde el principio de la soberanía nacional y su expresión programática, incluyendo cuestiones como su monarquismo, el respeto a la dinastía reinante, la estrategia insurreccional, el mantenimiento del orden o el restablecimiento de la milicia nacional, hasta el punto de mayor calado que suponía el cambio constitucional y la derogación de la constitución del cuarenta y cinco, habían sido templados o silenciados, al objeto de resultar lo más admisibles y atenuar las reticencias. Una estrategia que perseguía el ser considerado un partido de gobierno, que pudiera 
ser llamado, en un corto plazo, a formar ministerio. $Y$ es que los progresistas, y en esto coincidían con los moderados $^{15}$, se mantuvieron firmes en la defensa de un sistema bipartidista, cerrado a la participación de ninguna otra fuerza política, que tuviera como antagonista a un solo partido conservador. De ahí su tenaz oposición al proyecto originario del unionismo -acabar con los partidos tradicionales-, y su resistencia posterior a admitirlo como un partido más en el juego político; así como su afán de ver reconstituido un partido moderado "liberalizado", ajeno a su tradición reaccionaria y compatible con los presupuestos políticos del progresismo ${ }^{16}$. Pero no resultaba fácil, cuando la situación política parecía propicia para la llegada al poder de los progresistas ${ }^{17}$, prescindir de los prejuicios asentados en el imaginario conservador y permitir una acción de gobierno que, sin duda, superaría los límites de un sistema político que pretendían escasamente mudable ${ }^{18}$. De hecho, a pesar de las esperanzas que los progresistas tenían fundadas de ser llamados con prontitud al gobierno, confiados en el robustecimiento organizativo de su partido tras el regreso de los "resellados" y una opinión que creían mayoritaria a favor de una salida política reformista ${ }^{19}$, sus expectativas quedaron frustradas, precisamente, por la prevención de la que el moderantismo no tuvo capacidad de prescindir.

Fue la crisis ministerial ocurrida a raíz de los incidentes de las celebraciones del 2 de mayo la que vino a expresar, de manera fehaciente, la resistencia del frente conservador, incluyendo a figuras -disidentes y no disidentes- del unionismo, a admitir un gobierno progresista. Truncada la vía legal y directa, único modo de acceder al poder, el progresismo optó por una salida hacia delante, abandonando la estrategia complaciente mantenida hasta entonces y abanderando un programa claramente rupturista con el sistema político vigente ${ }^{20}$. Defendiendo ahora de forma abierta la reforma de la constitución, exigiendo la convocatoria de cortes constituyentes, venía a cerrarse la dinámica conciliatoria puesta en marcha desde julio de 1854. Las circulares dictadas por el gobierno de Miraflores ante la contienda electoral, mostraban la posición que moderados y unionistas iban a adoptar ante el envite del progresismo, despertando de nuevo las actitudes intransigentes que reavivaban, inevitablemente, el discurso preventivo del conservadurismo y el recurso al victimismo de los progresistas ${ }^{21}$. Previendo una exigua minoría, en caso de concurrir a las elecciones, efecto del uso de la consabida "influencia moral" del gobierno, el partido progresista decidió adoptar finalmente la política del retraimiento ${ }^{22}$.
Con esta estrategia, los progresistas renunciaban a participar dentro de la dinámica propia del régimen parlamentario, haciendo de su retirada <<un arma de combate, un medio de pelear que el gobierno ha puesto en nuestras manos $>>^{23}$, situándose en una posición difícilmente compatible con el respeto a la legalidad ${ }^{24}$. "Revolución pacífica", venían a denominarla los demócratas, congratulados por su reencuentro táctico con el progresismo y por la nueva etapa de convergencia que creían inaugurar ${ }^{25}$. Pero, a diferencia de aquéllos, los progresistas buscaban el restablecimiento de un sistema de partidos dual, en el que vinieran a turnarse en el poder con los moderados, sin buscar más alteración que el implantar una constitución aceptable para ambos, <<a fin de que al subir uno y otro no tengan necesidad de alterarla $>>^{26}$. Es más, todavía confiaban en que la crisis política que se atravesaba, y a la que contribuía definitivamente su retraimiento, no diera más opción que llamar a los progresistas al gobierno, sin tener que recurrir a ninguna otra vía: $<<$ Subiendo el partido progresista al poder de un modo pacífico, no habrá turbación alguna para su subida, ni él la producirá después, y por eso se verá lo que es en sí y lo que son sus principios, que podrá desarrollar tranquilamente $\gg{ }^{27}$. Esta posición mesurada del progresismo -que los demócratas constataban y repudiaban, y que suponía la limitación y perversión de sus ideales y principios-, colocaba a este partido en un mismo frente junto a la democracia, decidida hacia una política de total y plena "abstención"28. Una subordinación, sumisión si se quiere, de sus presupuestos y sus fines en aras de una posición táctica de la que, en el plazo de unos años, obtendrían los demócratas evidentes resultados, arrastrando la conjunción de ambas fuerzas políticas hasta la línea de la revolución ${ }^{29}$. No obstante, desde el partido democrático, no todos veían con la misma benevolencia la llegada del progresismo, recelosos de la conversión de un partido que seguía aspirando a ser poder bajo la monarquía de Isabel $\mathrm{II}^{30}$. Una ambigüedad que se mantuvo durante meses en el seno del partido progresista, efecto de puntos de vista encontrados, entre los que pretendían que el retraimiento no era sino una apuesta estratégica $y$, por lo tanto, circunstancial, puestas las ambiciones en una pronta llamada al poder, y los que abogaban por una postura rupturista, a pesar de las consecuencias seguras que traería una revolución.

Es cierto que, desde el fin del ministerio O'Donnell, hubo tendencias proclives a que los progresistas entraran a formar gobierno, criticando las medidas electorales que servían de justificación al retraimiento de progresistas y demócratas. El propio Moreno López, 
ministro dimisionario del gobierno de Miraflores, reconocía abiertamente el derecho usurpado al progresismo: <<Era la primera vez que en el espacio de treinta años había merecido el partido progresista el poder por las vías pacíficas y legales. Era la primera vez que se habría negado contra toda razón y derecho. Era la primera vez que podría haberse apellidado con verdad el partido desheredado. Era la primera vez que habría tenido, no razón, pero sí pretexto para convertirse en partido antidinástico. Era la primera vez que podía haber llamado a las puertas de la revolución con visos de justicia. Era la primera vez que el país habría podido ponerse de su lado para vengarle $>>^{31}$. Ausentes los progresistas del parlamento, los diputados se reconocían, efectivamente, miembros de fracciones heterogéneas, consecuencia de la ineludible "disolución de los partidos". De ahí que, conscientes de la imposibilidad de aglutinar mayorías con los principios y la organización de los antiguos partidos -y muy particularmente del moderado-, se hiciera necesario formar gobiernos de concertación o de coalición, en lo que algunos venían a identificar los nuevos propósitos y el nuevo significado de la unión liberal. Una forma de entender el unionismo despojado de la idea de partido que una parte importante de sus fieles concibieron, así como del proyecto político reformista y regenerador que albergaba, para convertirse en un simple procedimiento para la formación y mantenimiento de ministerios y la cohesión y amalgama de mayorías parlamentarias. <<He aquí el gran triunfo, la excelencia de la unión liberal -[clamaba Mena y Zorrilla en el congreso]-, y porque todos, cuando no son de unión liberal, quieren imitarla [...]. La agrupación se hace como la hizo la unión liberal, reuniendo grandes grupos, grandes ideas, estableciendo un dogma común en lo esencial, transigiendo en lo intransigible, en lo demás dejándolo a la libertad $>>^{32}$. Una concepción "bastarda" de la unión liberal de la que se sentía forma y parte el propio gobierno de Miraflores, encarnando aquel "panunionismo" que Cánovas tiempo atrás anunciara ${ }^{33}$, tal y como reconocía Rodríguez Vaamonde, ministro de la gobernación: $<<$ Yo nunca tuve la unión liberal en los labios, nunca. Yo lo que tuve en mis labios fue el deseo de que con los centros de la cámara se pudiera formar un partido, una agrupación poderosa que pudiera sostener un gobierno; de la unión liberal no hablaba; yo me ocupaba de ella porque había querido estrecharse mucho, reducirse demasiado, y se había pretendido unirla a un solo nombre, y yo no quería esa unión liberal; yo quería para mi patria una agrupación política anchurosa, donde pudieran entrar todos los elementos conservadores liberales del país; donde quedaran fuera los extremos del partido moderado; donde quedara fuera el partido progresista $>>^{34}$. Una perversión de la idea genuina de la unión liberal, que los aún verdaderos unionistas, más allá de las disidencias surgidas dentro de sus filas, defendían en su verdadero significado, distanciando sus auténticas expectativas con las pretendidas por este nuevo unionismo de bajo alcance -"pseudounionismo" o "unionismo apócrifo", como lo definiría Herrera ${ }^{35}$-. Así lo venía a manifestar Ulloa en las cortes: <<Nosotros queríamos hacer una fusión, y la haremos de seguro, porque lo sucedido habrá abierto a todos los ojos, y todos sabrán sacrificar cuestiones pequeñas en aras de ese gran pensamiento político. Vosotros no habéis hecho eso. ¿Sabéis lo que habéis hecho vosotros? Una coalición, primer acto parlamentario de este gobierno, cuando es el último recurso de la oposición. ¿Y sabéis qué es en política una coalición en el gobierno? Pues yo os lo diré en tres palabras: una mentira que va a lo desconocido por la desconfianza $>>^{36}$.

Se definía así el nuevo marco político que, hasta 1866, y muy especialmente el segundo gobierno de Narváez, iba a determinar y condicionar la dinámica partidista y parlamentaria. Sobre la común aceptación de un talante expresamente liberal, alejada toda tentación de adoptar posturas resistentes $\mathrm{y}$, mucho menos, reaccionarias, se impuso un lenguaje centrado -con mayor o menor sinceridad- en los conceptos de tolerancia y conciliación. Una pugna por el centro, una verdadera "competencia de liberalismo", como vendría a calificarla Mena y Zorrilla ${ }^{37}$, de la que no fueron capaces de sustraerse las distintas fracciones moderadas y unionistas, confundidas unas y otras bajo la común pretensión -y necesidad- de amalgamar unas mínimas mayorías ${ }^{38}$. Y aunque algunos "moderados históricos", tanto de las filas más conservadoras apegadas al "neísmo", ejemplificadas en Nocedal, como desde tendencias más liberales, como la representada por Silvela, se combatían los postulados diluyentes de este nuevo unionismo, base de alianzas y coaliciones, y se defendía la exigencia de reconstituir el sistema sobre los partidos tradicionales, esta estrategia conciliatoria y pro-liberal no era fácilmente prescindible ${ }^{39}$. Faltos de confianza en el restablecimiento de un sistema bipartidista, solo parecía conveniente y posible la reformulación de esa especie de unión liberal o, como vendría a bautizarlo Herrera, desde una posición escorada a la derecha, partido "conservador liberal": $<<Y$ en esta situación, ¿cuál es el interés de todos los que nos llamamos conservadores liberales? Estamos divididos, estamos separados por diferencias más o me- 
nos pequeñas; estamos distribuidos en grupos bajo distintas denominaciones. ¿Cuál es el interés de este gran partido que con una mano tiene que luchar con la revolución, y con la reacción con la otra [...]? ¿Cuál es la misión de este gran partido si no ha de comprometer las instituciones del país? Conciliar, transigir diferencias, estrecharse, establecerse sobre bases sólidas $>>^{40}$. El propio Narváez, la figura más caracterizadamente resistente y reaccionaria, se veía obligado a recurrir, en este nuevo clima político, a la táctica de la tolerancia y la conciliación: $<<$ Yo he sido político de resistencia cuando el país la ha necesitado; pero hoy la resistencia labraría mi descrédito, y eso es lo que buscan mis émulos, anularme para siempre. [...] si S. M. me llama, acudiré con apresuramiento y cogeré el mando con gusto por el placer de dejar al duque de Tetuán con un palmo de narices, porque voy a ser más liberal que Riego, porque como hoy no llueven progresistas a chaparrones, puedo salir a la calle sin paraguas y en mangas de camisa $>>^{41}$. De tal manera que hasta los diputados que seguían considerándose miembros del partido moderado, abjuraban de la política de resistencia abanderada por Nocedal, que trataba de simbolizar en su postura reaccionaria las esencias tradicionales del moderantismo ${ }^{42}$.

En este escenario marcadamente liberal y pretendidamente conciliador, el retraimiento de los progresistas provocaba una clara inconsistencia entre el discurso y la realidad política. De ahí que la reintegración de este partido a la arena parlamentaria se convirtiera en el tema central del debate político, utilizada como argumento principal en la "pugna de liberalismo" en el que combatían las distintas fracciones presentes en el parlamento ${ }^{43}$. Hasta un moderado recalcitrante como Benavides, enemigo de las tendencias conciliatorias en boga y defensor del bipartidismo, ponía sus esperanzas, además de en la resurrección del partido moderado, en el próximo regreso de los progresistas: $<$ El partido moderado no puede existir sin el partido progresista enfrente, porque el partido moderado es un partido de doctrinas; a reconstruirle pues dejándose de esos términos medios que no sirven para nada más que para crear la confusión en que hemos estado. Lo siento en el alma que el partido progresista no esté aquí; entonces nos uniríamos para resistir al enemigo común; con lealtad y con franqueza procuraremos todos que el partido progresista tenga las condiciones convenientes para gobernar; y el día que el partido progresista, reorganizado, se presente en lucha, el partido moderado estará en la brecha. No puede existir uno sin otro; tienen condiciones iguales, tienen una misma existencia; son dos gemelos que nacieron en un mismo día, y vendrán a morir en un mismo día $>>^{44}$. Pero para conseguir mover al progresismo de su retraimiento era necesario admitir un espacio de concesiones que, muy difícilmente, moderados y unionistas convendrían en aceptar. Entre estas, debía admitirse, además de una nueva ley electoral que garantizase una presencia parlamentaria capaz de neutralizar la habitual "influencia moral" del ministerio en cuestión, el planteamiento de un cambio constitucional, abriendo la posibilidad de prescindir de la constitución vigente y reinstaurar bien la constitución de 1837 , bien la nonata de $1856^{45}$. Pero la reapertura del proceso constituyente no estaba en las miras ni en las conveniencias del grueso de las fuerzas políticas, desde el centro a la derecha, de las distintas fracciones representadas en la cámara. Los sucesivos cambios de gobierno que se produjeron venían a cerrar toda opción a remover el texto constitucional. El breve gobierno presidido por Arrazola, que si bien se consideraba "moderado histórico" se declaraba, al mismo tiempo, "templado y conciliador ${ }^{46}$, y el posterior ministerio de Mon -con Cánovas en la cartera de gobernación-, de clara filiación unionista, mantuvieron la línea tolerante y conciliatoria iniciada, pero sin dar opción a modificar la constitución de $1845^{47}$. La derogación de la reforma constitucional de 1857, aprobada finalmente bajo este último gobierno, servía antes para aglutinar a la mayoría parlamentaria que para disponer al progresismo a favor de una improbable reincorporación en el juego político ${ }^{48}$.

En el lenguaje político del progresismo, el sometimiento a la legalidad vigente no escondía su explícita decisión por modificar la constitución y restablecer el texto de 1837. Y aunque todavía mantenía una mínima confianza en ser llamado a formar gobierno, fue progresivamente introduciendo en su discurso, eso sí, con voluntaria ambigüedad -y hasta con confusa complejidad-, la opción de una futura revolución: <<Se dice que para variar de política habría necesidad de hacer una revolución. Sí, en el buen sentido de la palabra. Es necesaria una revolución que establezca el orden, hoy subvertido. Esa revolución puede ser pacífica o violenta. Para hacerla pacífica basta el nombramiento de un ministerio y la publicación de un real decreto que destruya el obstáculo que impide la alternativa de los partidos en el poder. Si no se acepta la revolución pacífica, la revolución violenta vendrá o no vendrá; pero si no viene la revolución violenta política, será porque venga la revolución social, que solo la revolución política puede impedir $>>^{49}$. En el multitudinario banquete de los Campos Elíseos de Madrid, todo un alarde de fuerza del progresismo, Prim presentaba, antes 
de lanzar su memorable profecía, las dos vías abiertas al progresismo: <<Si el gobierno actual o el que le suceda nos abre el campo electoral; [...] si renuncia a ejercer la no menos bastarda influencia moral; si nos da, en fin, garantías de que las elecciones serán libres, completamente libres, podremos ir a las elecciones; y si no vencemos en las primeras cortes que se nombren, vendrá una muy fuerte minoría que preparará el terreno para que a otras elecciones venga mayoría. $\mathrm{Si}$ no sucede nada de eso; si los hombres del partido moderado o de la unión, que para nosotros viene a ser lo mismo, vuelven a las trampas, a la coacción, a las violencias electorales, considerándonos parias como hasta aquí; entonces, fuertes en nuestra conciencia de haber sido resignados y transigentes hasta el fin para evitar males a la patria, fuertes en la razón que tendremos en justicia y el derecho que estarán por nosotros, y fuertes, en fin, en la fuerza que tenemos, levantaremos erguidos la cabeza, haremos una declaración solemne $>>^{50}$.

Pero esta posición, aunque velada, desafiante, iba a ser aprovechada por aquellas fracciones poco proclives a las tendencias conciliatorias, que exigían una actitud intransigente frente a un partido que se atrevía a expresar tan abiertamente su repudio al marco constitucional $^{51}$. A pesar de las acusaciones que se lanzaban contra los progresistas de conspirar y alentar insurrecciones, La Iberia mantuvo la estrategia del "todo o nada", a sabiendas de que el acceso al gobierno por medios legales -más allá de los últimos cantos de sirena- resultaba imposible y que solo había opción de alcanzar el poder por medio de una revolución ${ }^{52}$. La subida al gobierno de Narváez y la convocatoria de elecciones, reabrió nuevamente la oportunidad de que los progresistas salieran de su retraimiento ${ }^{53}$. El duque de Valencia, tal y como había anunciado, puso en acción una política amable y benevolente, al objeto de conseguir lo que sus antecesores no habían logra$\mathrm{do}^{54}$. Pero el partido progresista, renovado en su cuadro dirigente ${ }^{55}$, se mantuvo firme en su retraimiento electoral: $<<$ Se nos halaga con el turno pacífico en el gobierno, y los obstáculos tradicionales son el reaccionario grito de guerra, cuando la opinión pública señala al partido progresista como única tabla de salvación en las tormentas que, rugiendo, pasan y vuelven sobre la patria amada. Se nos brinda con legalidad en las elecciones, y no bien articulada la promesa [...] el derecho electoral abdica y la esperanza de todo bien desaparece. Se nos amenaza con ponernos fuera de la ley si no luchamos, y aparentan desconocer que nuestro estado normal es vivir fuera de los consejos de la corona, y olvidan que no usar del sufragio es acto lícito en la moral y legítimo en el derecho $>>^{56}$. Fracasado este último intento, Narváez corregía el talante conciliatorio exhibido en la contienda electoral para implantar una política represiva, especialmente en lo relativo a la cuestión de imprenta, que, a fin de cuentas, le resultaba más propia y ajustada. De hecho, la política tenue y contemplativa ejercida había provocado no poca perplejidad, y hasta desazón, en diversos elementos del partido moderado ${ }^{57}$. La política reaccionaria que vendría a imponerse a partir de entonces, claramente inspirada en las demandas apocalípticas de los "neos", no hacía sino confirmar al progresismo en la estrategia de la revolución ${ }^{58}$. Como expondría el propio Narváez: <<Es preciso poner a cubierto el trono de nuestra reina, la persona del monarca, la dinastía, el decoro público, la paz de la familia, la honra de las gentes y el sagrado de la vida privada. Los abusos que se cometan contra las instituciones, es preciso contenerlos con mano fuerte, castigarlos con energía, porque si seguimos como hasta aquí, nos iremos connaturalizando con esos excesos, y poco a poco llegaremos al punto que se extinguirán en nuestro corazón hasta el último átomo del honor y de la vergüenza $>>^{59}$.

Ni siquiera el retorno de O'Donnell a la jefatura del gobierno en junio de 1865, con la puesta en acción de medidas cargadas de simbolismo para engatusar a los progresistas, tales como el reconocimiento del reino de Italia, la aprobación de una nueva ley electoral, la retirada de la ley de imprenta elaborada por el anterior ministerio o las que buscaban reducir la influencia de la camarilla sobre la reina, alcanzaban a reconducir a los progresistas ${ }^{60}$. Pues si bien la salida de Narváez podía significar un giro en la política reaccionaria con la que no podía dejar de asociarse, el unionismo representado por el conde de Lucena no ofrecía al progresismo ninguna garantía para la efectiva liberalización de la situación ${ }^{61}$. De ahí que cualquier política u ofrecimiento que hiciera el nuevo ministerio se viniera a estrellar contra la intransigencia de los progresistas, en un punto sin retorno que no les iba a sacar del retraimiento ${ }^{62}$. El 3 de enero de 1866, el general Prim comandaba una sublevación militar, a la postre fracasada, en Villarejo de Salvanés, que daba por finiquitado el período de las experiencias conciliatorias. Llegaba, de nuevo, el turno a la revolución.

\section{EL "FUSIONISMO": LA ESTRATEGIA IMPERFECTA DE LA CONCILIACIÓN LIBERAL}

Los "sucesos de Natal" de 1861, acaecidos a raíz de la muerte de Pedro V y de dos de sus hermanos, pu- 
sieron en cuestión, después de una década de funcionamiento, la estabilidad política inaugurada desde el triunfo de la Regeneração. No se trataba de una mera cuestión de orden público, sino de la debilidad o vulnerabilidad de un gobierno que, debido a los apoyos recibidos de los medios populares, fruto de las coaliciones que cobijaba, no era capaz de asentar una política vigorosa y coherente. Es cierto que, desde los inicios de la Regeneração, los principios de tolerancia y conciliación tuvieron una perfecta aplicación sobre los partidos históricos, acabando con las antiguas pugnas partidistas, integrando a antiguos enemigos políticos bajo una nueva cultura política común. Una especie de reformulación del primigenio liberalismo, resucitando la "unión de la familia portuguesa", por medio de uniones, coaliciones y agrupaciones "pasteleiras" que bien podemos considerar efecto del "fusionismo". Un concepto político que, sin ser novedoso -y a pesar de las connotaciones que recibiría a partir de septiembre de $18655^{-63}$, venía a identificar, sobre la renuncia a las tendencias exclusivistas, la permeabilidad de las fronteras partidarias, la transformación de las antiguas filiaciones y la agrupación de personalidades de signos dispares, más allá de sus antiguas $-\mathrm{y}$ también presentes- identificaciones políticas. Pero lo que había servido para terminar con la era de violencia partidista ${ }^{64}$ y regenerar, en gran medida, el sistema político, no solo no facilitaba la nueva articulación de los partidos, sino que hasta dificultaba el funcionamiento del parlamentarismo.

La reformulación de las antiguas fuerzas políticas, transmutadas en los partidos histórico y regenerador, había generado entidades de escasa solidez, en las que se aglutinaban tendencias y fracciones heterogéneas. La vaguedad de sus principios ideológicos y la escasa diferenciación programática con sus pretendidos antagonistas, manteniendo una notable contigüidad las políticas de uno y otro partido en las tareas de gobierno, no facilitaban ni la identificación política ni la cohesión interna. Por otra parte, el mantenimiento de una tendencia pretendidamente conciliatoria y "fusionista", que favorecía antes la flexibilidad y la ductilidad de los partidos que el retorno a los maximalismos y la confrontación, y que constituía el fundamento para la realización de amalgamas y coaliciones, provocaba la inconsistencia de estas nuevas agrupaciones políticas. Una fragilidad que se hacía notar en las políticas ministeriales de uno y otro partido, como ocurrió con el breve gobierno regenerador de Terceira y Aguiar (de marzo de 1859 a junio de 1860) o con su antecesor, el ministerio histórico presidido por Loulé desde julio de $1856^{65}$. Y es que a la altura de 1861, no se planteaba siquiera la posibilidad de consolidar un sistema basado en el bipartidismo, ni opción había para poder materializarla, dado el estado en el que se encontraban los partidos y la resistencia existente a resucitar una dualidad política que, vivas todavía las consecuencias nefastas que había provocado, se creía prescindible.

La prematura muerte de Pedro V y, especialmente, los conflictos que se sucedieron ante el cúmulo de infortunios que aquejó a la familia real, iban a poner en cuestión la conveniencia y efectividad de unos principios que, ya entonces, empezaban a considerarse inconvenientes $^{66}$. El gobierno de Loulé, que con la presencia en el ministerio de Ávila y Carlos Bento -excartistas que formaban una filiación propia67- encarnaba perfectamente ese espíritu "fusionista", se veía obligado -en febrero de 1862- a defenestrarles para contener las demandas de los radicales, que lideraban la base social de los históricos y de quienes dependía para su sostenimiento ${ }^{68}$. Y es que dentro del partido histórico se había ido desarrollando una corriente "proto-republicana", exigente de una mayor firmeza doctrinal que pretendían se tradujera, por vía ministerial, en políticas activas acordes con los principios secularizadores y "republicanizantes" con los que se identificaba ${ }^{69}$. Su involucración en la organización de los acontecimientos de diciembre, a través de la Asociación Patriótica que controlaba y dirigía, mostraba el grado de incompatibilidad que empezaba a manifestarse entre la "unha branca" y la "unha preta", las vertientes moderada y radical que conformaban, en difícil convivencia, este partido. De hecho, Loule no tuvo más remedio que mostrarse excesivamente suave y taimado en cuanto a las medidas de represión y castigo de los responsables de los "sucesos de Natal", a sabiendas de su connivencia con los líderes de la Asociación Patriótica, cuyos dirigentes y miembros lo eran también de la mayoría que lo sostenía ${ }^{70}$.

De tal modo el gobierno y la corriente moderada que representaba se sentían rehenes de los radicales, que el recambio ministerial se hizo bajo las directrices de José Estevão, convertido en la personalidad más influyente de entre las fuerzas democráticas y en el mayor condicionante de la política elusiva e inconsistente de Loulé. El nombramiento de Mendes Leal y de Lobo D’Ávila como nuevos ministros, representantes ambos de la "unha preta", mostraba la línea condescendiente del ministerio y su falta de vigor para defenderse de la oposición, aquejada igualmente de falta de solidez para convertirse en alternativa de gobierno $^{71}$. Pero ni siquiera la formación de un gobier- 
no monocolor, superada toda tentación "pasteleira", integrando todas las corrientes del partido histórico, desde los más atemperados como Sá da Bandeira, Braancamp o el propio Loulé, hasta el radicalismo encarnado en los nuevos ministros, iba a dar mayor firmeza al ministerio. Esta experiencia gubernativa demostró que no había suficiente fuerza política para imponer, en esas tempranas fechas, un programa político radical ${ }^{72}$. De hecho, el radicalismo, a pesar de su nueva presencia ministerial, seguía siendo el principal elemento desestabilizador. Su mantenimiento dentro del partido histórico, sin formar una agrupación autónoma e independiente, si bien marcaba los límites de su acción política y evitaba toda deriva revolucionaria, había escorado la acción del gobierno hacía una política más extremada, y ello en un contexto común ya de por sí caracterizadamente progresista. Su influencia seguía haciéndose notar en las distintas esferas políticas, desde la propia monarquía, que venía a enlazarse con la impía dinastía de Saboya ${ }^{73}$, hasta las distintas manifestaciones públicas que continuaba promoviendo, por medio de las asociaciones que controlaba, los clubes, los centros electorales y la propia masonería, en línea con su programa de construir una nueva ética cívica a través de la ideologización de las masas ${ }^{74}$.

Si el radicalismo había supuesto para Loulé una base sociopolítica indispensable sobre la que asentar su preponderancia, no era menos cierto que representaba, para el gobierno y para el propio régimen político, un preocupante foco perturbador. Una situación frágil, dado el estado de los partidos, que bien pudiera ser aprovechado por quien pudiera capitalizar la movilización popular existente y dispusiera de la influencia y el poder suficientes como para provocar un cambio o liderar un golpe. Y ese personaje parecía identificarse con el mariscal Saldanha, el prohombre de la Regeneração, que gracias a su enorme versatilidad, su preeminencia militar y su abierta popularidad parecía el elegido. En el gran mitin de 10 de marzo de $1861^{75}$, orquestado por la Patriótica, Saldanha $-y$ no Loulé- había sido el aclamado para servir de ariete frente a la pretendida reacción y avanzar por la senda liberalizadora. En los recientes sucesos de diciembre de 1861, se identificaron varios responsables afines al propio duque, llegándose a plantear incluso su responsabilidad en el mismo ${ }^{76}$. Con cierto fundamento podían mirar los partidos con recelo la figura del mariscal, dado que Saldanha venía a identificarse él mismo como una figura salvífica, por encima de los partidos y del propio sistema parlamentario, ofreciéndose al entonces Pedro V para liderar, en comandita, una especie de dictadura ministerial ${ }^{77}$. Con la salida de Saldanha de Lisboa, que Loulé alcanzaba gracias a un goloso puesto al frente de la legación portuguesa en Roma, se conseguía neutralizar, por el momento, cualquier tentativa de golpe militar ${ }^{78}$. Incluso en su ausencia, su nombre volvería a sonar en las voces de los amotinados de la región del Minho -la revuelta de María Bernarda- y en la intentona insurreccional de Braga, levantamientos populares de inspiración nada radical, antes al contrario, críticos contra el gobierno de Loulé y las medidas fiscales adoptadas -herencia, por otra parte, del anterior ministerio-, que fueron, en esta ocasión sí, duramente reprimidos ${ }^{79}$.

Pero el movimiento radical iba a seguir condicionando e influyendo la política del gobierno, cuya posición se había debilitado más aún con la salida de los avilistas, que acrecían el número de opositores en las cámaras. Y es que Loulé no podía desprenderse de los radicales, en una coyuntura en la que estos, bajo el liderazgo de José Estevão, insatisfechos con la política ministerial y conscientes de su peso y de la creciente identidad que albergaban, trataban de establecer una fuerza política propia. <<Pretendemos reconstruir, por medio de buenas adherencias y simpatías, ampliar el partido progresista, congregando todos los elementos de él dispersos por los diferentes gremios que las circunstancias crearan, tomando por núcleo de esta agregación política la parte de ese gran cuerpo que juzga necesario poner término a sus concesiones y tornar a su natural servicio de velar por las cosas públicas, apreciándolas no por el antiguo prisma de aquel partido, que no podía quedar inmutable, sino según están enseñando la experiencia de los acontecimientos y el influjo de los tiempos $>>^{80}$. Lo que suponía dar resurrección a los antiguos partidos y retroceder a la lucha política que había logrado pacificar la Regeneração, una vuelta al partidismo que no era fácil restablecer. $<<$ El retroceso para ese sistema -[respondía el diputado regenerador Martens Ferrão en la cámara, contestando precisamente a José Estevão]- sería imposible, porque no se pierde una conquista feliz de las ideas, sustentada desde hace muchos años. No se pierde así el resultado del trabajo consecutivo de once años en el que los hombres públicos que se preocupan del bien de este país, se han empeñado en olvidar el viejo exclusivismo de los partidos, con sus odios y con sus intolerancias $>>^{81}$. Pero el grueso de la clase política que formaba los nuevos partidos políticos no estaba dispuesto a prescindir de los principios fusionistas y conciliatorios que habían logrado imponer sobre el exclusivismo partidista, ni iban a permitir el reavivar un proceso constituyente que el Acto adicional, con sus evidentes limitaciones, había logrado cerrar ${ }^{82}$. 
De cualquiera de las maneras, Loulé se vio obligado a ceder más aún ante el influjo del radicalismo, decidiéndose finalmente a integrar a José Estevão en el ministerio, a costa de la línea templada del partido, viniendo a sacrificar a Sá da Bandeira y Braamcamp, lo que expresaba el grado de subordinación y la debilidad política de los históricos, incapaces de sostenerse sin el soporte de las fuerzas democráticas. La muerte del líder radical ${ }^{83}$, sin llegar siquiera a tomar posesión de su nuevo cargo, que anulaba la mudanza ministerial anunciada, ponía aún en mayores dificultades al gobierno, al descabezar a los radicales y dejar a Loulé sin uno de sus más eficaces apoyos, una situación de fragilidad ni siquiera compensada con la nueva remesa de pares concedida por D. Luis. El cambio de gobierno no vendría a materializarse sino hasta enero de 1864 , labrándose cada vez más las desavenencias existentes entre la "unha branca" y la "unha preta" y marcando el predominio de esta en la política errática de Loulé ${ }^{84}$, que desde tiempo atrás daba muestras de agotamiento y cuya resistencia a ceder el poder provocaba el desquiciamiento de las oposiciones ${ }^{85}$. También en el seno de los radicales, que mantenían su apoyo al gobierno, pesaba la colaboración con un ministerio que respondía solo mínimamente a sus proyectos y expectativas. Latino Coelho, que tras la muerte de José Estevão se había convertido en la imagen destacada de aquel "partido nuevo" al que los demócratas aspiraban, se veía obligado, por sus diferencias e insatisfacciones con la mayoría histórica de la cámara, a renunciar a su acta de diputado ${ }^{86}$. Una posición que planteaba los riesgos e incertidumbres a los que se enfrentaba el gobierno, dado el proceso rupturista que venían a trazar los radicales, dejando a Loulé sin las bases sociales y políticas que le daban cuerpo y cobertura. Pero también para el futuro próximo del propio régimen político, al presentar el radicalismo una vía política propia, desintegrada de los partidos medios y proyectando un horizonte que superaba los límites establecidos por la Regeneração. Por medio de los clubes, los centros políticos, las logias masónicas, la prensa y otras formas de socialización y movilización, el radicalismo, que no cejó en su tarea educadora y proselitista, favorecía la creación de un clima revolucionario que ponía en cuestión la calma política existente ${ }^{87}$. Un escenario especialmente proclive para la materialización de diversas expresiones populistas, que entraban en competencia con los partidos políticos, las únicas fuerzas políticas que daban sustento al sistema parlamentario, a las que de una forma u otra trataban de suplir.

Las elecciones con las que Loulé trató, en septiembre de 1864, aplacar las críticas de las oposiciones y dar una mínima cohesión al partido histórico, carente de unidad y de más aglutinante que el conseguir un acta de diputado, no iban a dotar al gobierno de mayor solidez ${ }^{88}$. El escándalo en el que se vio envuelto el ministro de hacienda, Lobo d'Ávila, el líder de la "unha preta", que representaba la fracción del radicalismo todavía dispuesta a mantenerse dentro del partido histórico, iba a provocar su salida del gobierno junto a su compañero de filas, Mendes Leal, y la disolución definitiva de los lazos políticos que habían unido, en constante desarmonía, una y otra tendencia ${ }^{89}$. Lejos de rendirse a la situación, Loulé, incombustible, recomponía con políticos de segunda fila el ministerio, tratando de mantener en pie una situación a todas luces insostenible ${ }^{90}$. Ni la actitud contemplativa de la oposición regeneradora ni el apoyo inquebrantable del monarca podían hacer sobrevivir un gobierno que no tenía razón de ser, habiendo perdido toda base política sobre la que asentarse. Una situación de crisis que, dada la particular situación política del Portugal de la Regeneração, no desembocaba, como habría ocurrido en otros países, en una revolución: <<Sin agitar esta crisis las entrañas de la sociedad portuguesa - [trasladaba el Ministro de España en Lisboa, Diego Coello y Quesada]-, ha preocupado, sin embargo, lo bastante la atmósfera política del país, y demostrado la profunda división que trabaja al partido dominante y la disolución verdadera en que están todas las antiguas parcialidades políticas. En las cortes, como en la sociedad portuguesa hay grupos, individualidades, ambiciones y antagonismo de personas, no hay partidos ni verdaderas y radicales diferencias de ideas y de principios. Pero si este es un mal muy grande en todos los pueblos lo es aquí menor por el respeto que generalmente se profesa a la ley, por las consideraciones que se guardan los hombres públicos y por la falta de verdadero ardor que hay en la lucha de sus parlamentos. La estabilidad de la administración y la tolerancia que reina en las regiones oficiales, como la calma hija del temperamento del pueblo son además grandes elementos de orden, de libertad y de paz $>>^{91}$.

Obligado finalmente a dimitir, el ministerio de Loulé dio paso a otro presidido por Sá da Bandeira, una reliquia del régimen liberal que trataba, infructuosamente, mantener en pie esa aparente dualidad política centrada en los partidos histórico y regenerador. Revitalizando ese amago "fusionista" que suponía la presencia del conde de Ávila y de Carlos Bento, el nuevo gobierno se encontraba completamente desamparado, sin recibir el beneplácito de la mayoría histórica de la cámara y sin disponer de la aquiescencia de los regeneradores ${ }^{92}$. A pesar de los intentos de Ávila 
por alcanzar el apoyo de los regeneradores y de Sá da Bandeira por reunir a los históricos, el grueso de las filas de una y otra fuerza política se opusieron a lo que entendían no era sino una mera coalición parlamentaria y ministerial, una situación interina sin más trascendencia en la reorganización de los partidos políticos $^{93}$. Y es que en esa precisa coyuntura, los líderes de ambas fuerzas políticas creían imprescindible volver a las esencias de la Regeneração, restableciendo una verdadera "fusión" de los partidos, creando nuevamente una única fuerza liberal progresista que se superpusiera a las fracciones que se habían ido conformando en torno a históricos y regeneradores. Una nueva dimensión política que el singular diputado Vieira de Castro supo explicitar perfectamente en la cámara: <<Me parece necesaria, improrrogable y urgentísima la creación de un nuevo partido que debe levantarse de la fusión de todos los partidos, menos el conservador, que tiene su misión a cumplir, y que en los buenos residuos de esta amalgama juntará nuevas y viejas adhesiones que han de honrarlo y fortalecerlo. Este partido, que debería llamarse el partido progresista, había de confundir en el primer abrazo, sincero y espontáneo, todos los grandes talentos y todas las grandes virtudes del partido histórico, todos los grandes talentos y todas las grandes virtudes del partido regenerador. Es preciso hacer solemne hecatombe, en las aras de la patria, de estos odios diminutos e insignificantes en los que hoy se divide y se descompone la más soberbia y opulenta porción de la familia portuguesa $>>^{94}$.

Como respuesta a la formación de un frente "fusionista", el gobierno de Sá da Bandeira recibía la colaboración multiforme de las tendencias que veían peligrar, en un futuro orden de cosas bajo el control comanditario de históricos y regeneradores, su supervivencia y posición. Las tendencias extremas, desde los irreductibles cartistas a los radicales, pasando por el pragmatismo de los avilistas y la "unha preta" de Lobo d’Ávila, unían sus fuerzas ante una situación que iba a significar, sobre todo para estos últimos, su distanciamiento del poder, quedando los partidos medios dueños y señores del centro político, sin recibir el contrapeso del radicalismo. Luis I permitió a Sá la disolución del parlamento, lo que suponía salvaguardar temporalmente la situación de un acceso revolucionario, manteniéndose los radicales a favor, y no en contra, del gobierno ${ }^{95}$. Pero ni el conde de Ávila ni Lobo d'Ávila suponían un sostén suficiente para mantener el gobierno de Sá, pues si bien el radicalismo, influyente y poderoso en cuanto a su ascendencia sobre las masas populares, apoyaba al ministerio frente la nueva tentativa "fusionista", estos ministros no despertaban ninguna confianza en ese cuerpo multiforme e inorgánico. Una situación que no hacía sino ahondar la crisis política existente, tal y como apuntaba Coello y Quesada: <<Pero, ¿qué vendrá detrás? Como no hay una bandera definida ni por parte del gobierno, ni por parte de las oposiciones que le combaten; como todos los partidos antiguos están disueltos; como las fracciones de estos mismos partidos se coaligan y se separan para destruir, y vuelven a separarse y coaligarse, para cuando empieza a vivir aquello mismo, que deseaban pocos días antes, no es posible calentar el desenlace, de todas maneras funesto para el país, de estas situaciones anormales y transitorias. Ayer las disidencias, que en ambas cámaras representaban el conde de Ávila, Aguiar y Lobo d'Ávila, principalmente, ayudadas por el partido regenerador y por los conservadores, derriban al gabinete Loulé, ya quebrantado por una lucha intestina; hoy la Regeneración, el partido cartista y los amigos del duque de Loulé, parecen unirse para derribar el gobierno, principalmente apoyado por las últimas disidencias $>>^{96}$.

El triunfo electoral de los "fusionistas"97, es decir, de los históricos y los regeneradores coaligados, resultaba, a ojos del representante español, la mejor garantía para la tranquilidad política, amenazada por los rumores de una pronta revolución en el país vecino: $<<$ Es indudable que la atmósfera de este país está profundamente preocupada de la eventualidad de una revolución en la península, siendo esta una de las causas que más vivamente hacen desear a sus verdaderos hombres de estado la constitución de un gobierno poderoso y fuerte, y que, a sus sentimientos a favor de la libertad, una el apoyo de los elementos conservadores. Una fusión entre el partido regenerador, y el antiguo partido cartista, aprovechando los elementos de orden que existen en el progresismo histórico, es sin duda la solución más vivamente deseada por el sentimiento público, y de ello es una prueba elocuente el éxito, que han tenido los candidatos del partido regenerador en las recientes elecciones parciales de Oporto y de Lisboa $>>^{98}$. Visto el desenlace electoral, Sá da Bandeira no tuvo más remedio que rendirse a la situación, dado que la única opción de mantenerse en el gobierno era recurriendo a Saldanha, ofreciéndole la jefatura del ministerio, salida que no cumplía las expectativas del mariscal, que solo aceptaría el mando asumiendo poderes excepcionales, algo que ni el rey ni el resto de las fuerzas políticas estaban dispuestos a aceptar ${ }^{99}$. En septiembre de 1865 , verificada la crisis del gobierno, Luis I llamaba al duque de Loulé y al conde de Castro, líderes del partido histórico, y a 
Joaquim António de Aguiar, jefe de los regeneradores, para encargarles, bajo la presidencia de este último, la formación de un gobierno de "fusión"100. El nuevo ministerio, en aplicación de los principios "fusionistas" que abanderaba, optó por no disolver la cámara, ni necesidad tenía de ello, dado el rápido transfuguismo que siguió a la dimisión de Sá. La "fusión" consiguió así adormecer y neutralizar toda oposición, que pasó a formar parte de la mayoría del gobierno, desarmando a las distintas fracciones que habían ido formándose en la lucha parlamentaria, creando una sensación, no del todo falsa, de calma política.

\section{CONCLUSIONES}

Todo parecía indicar que en Portugal, a diferencia de lo que estaba ocurriendo en España, el régimen político, y con él la propia dinastía, se encontraban completamente a salvo de todo riesgo revolucionario. La puesta en acción de los principios conciliatorios y "fusionistas", que de hecho no se habían abandonado completamente desde su integración en la cultura política que la mayor parte de las fracciones políticas compartían, había propiciado una especie de segunda Regeneração. Los distintos síntomas de inestabilidad que habían ido asomando, al calor del movimiento de los radicales, parecían sofocarse, distendiendo la tensión política e ideológica que habían introducido en el campo de la discusión política. Pero la estrategia conciliatoria que tan buenos resultados había dado en 1851 no iba a resultar la más conveniente catorce años más tarde. Es cierto que el "fusionismo" resultaba eficaz a corto plazo, asegurando la estabilidad política y el consenso entre los distintos partidos, dejando cerrada toda cuestión constituyente y aun de reforma del régimen vigente. Pero el recurso a la "fusión" impedía, nuevamente, la formulación de un sistema de partidos dual, que pudiera basarse en la alternancia y sobre el que pudieran rotar dos fuerzas políticas mayoritarias. En esos momentos, confundidos históricos y regeneradores en un mismo partido "progresista", no resultaba fácil establecer con qué otro partido debía disputarse la gobernación del estado, y eso considerando esta mixtura, dada su indudable heterogeneidad, como un partido mínimamente unido y con identidad propia.

Pero más preocupante resultaba la posición en la que venía a encontrase ese mundo multiforme que conformaba el radicalismo, que carente de organización y de ideología definida, suponía un magma inquietante en busca de un espacio sobre el que canalizar sus proyectos y aspiraciones. Una base socio- política propicia sobre la que vendrán a ensayarse, en los años siguientes, acciones populistas y formulaciones partidistas, que tratarían de dotarle de cuerpo e identidad política propios ${ }^{101}$. Y es que el mundo radical, mientras estuvo solapado al partido histórico, se mantuvo neutralizado en sus propósitos reformistas y democráticos, compartiendo tareas de gobierno y mayorías parlamentarias, lo que provocaba su moderación y dificultaba su unidad y organización. A cambio, se aseguraba su total fidelidad al régimen político y a la dinastía reinante, considerando a Luis I un verdadero rey republicano. No por casualidad, Luis I, como su hermano Pedro V, habían preferido gobiernos históricos, no permitiendo que la izquierda dinástica dejara de serlo, a diferencia de lo ocurrido en España con Isabel II y los progresistas, empujados estos al anti-dinastismo y a los demócratas a declararse, en una amplia mayoría, abiertamente republicanos. Pero con el nuevo gobierno de "fusión" el radicalismo se quedaba sin apenas opción en el juego parlamentario, lo que le llevaba a buscar nuevos espacios para su expresión política, libre de contenciones y mesuras, dejando abiertos sus anhelos reformistas por no llamarlos revolucionarios ${ }^{102}$. No obstante, por el momento, en Portugal seguía ensayándose la vía de la conciliación ${ }^{103}$.

En España, desde 1863, fracasado el proyecto genuino de la unión liberal, siguió empleándose un lenguaje político basado en la conciliación y en la necesidad de liberalizar la situación. Una política balsámica que respondía esencialmente a las dificultades y carencias que atravesaban moderados y unionistas, necesitados de propuestas que ayudasen a aglutinar las fracciones en las que se dividían y a mantener, con evidente fragilidad, las débiles mayorías que sustentaron a los gobiernos que se sucedieron. Pero esta inercia conciliatoria, que neutralizaba, eso sí, la tradicional política de resistencia defendida por el moderantismo, resultaba completamente insuficiente para atraer al progresismo, que vio cómo se fueron frustrando sus claras expectativas de ser llamado al gobierno. A diferencia de lo ocurrido en Portugal, el unionismo no alcanzó a disolver completamente los partidos históricos, consiguiendo progresistas y moderados mantener sus identidades políticas y sus aspiraciones de poder. Una pugna política en la que entraba además la unión liberal, convertida en partido, que venía a encarnar los principios de conciliación, materializando un programa que debía haber constituido la base de una cultura política compartida y no una fuerza política más en el escenario de los partidos. Esta nueva situación -de tres o cinco partidos, si incluimos al carlismo y a los demócratas- hacía improbable 
una dinámica de alternancia, que exigía una estructura claramente dual, lo que relegaba a los progresistas fuera del acceso natural a los consejos de la corona. $Y$ es que la propia monarquía -y los centros de opinión y decisión a los que estaba sujeta- no fueron capaces de prescindir de sus recelos ante un gobierno progresista, a pesar de los esfuerzos hechos por este partido para ser considerado ministerial, posición que marcaba las diferencias con la vecina dinastía de los Bragança. Una resistencia que iba a marcar el rumbo anti-dinástico que acabaría adoptando el progresismo.

Sin la posibilidad de formar parte del gobierno, los progresistas difícilmente podían aceptar un régimen que le cerraba sus puertas, lo que permitía un mayor protagonismo a las tendencias menos contemplativas, sobre las que los demócratas ejercían mayores influencias. De ahí que, primero como estrategia, medida de fuerza y presión, y, al mismo tiempo, como solución de ruptura, vista la intransigencia de los gobiernos moderados y unionistas, el progresismo fuera caminando por el retraimiento y desembocando en la revolución. Esto suponía declarar abiertamente su oposición a la constitución de 1845, sin plantear ninguna opción mesurada ante un texto que, de otro modo, tal vez hubieran estado en trance de respe- tar, como los históricos -y aun los radicales- habían sido capaces de aceptar en Portugal. De ahí que se plantease nuevamente la cuestión constituyente en el debate político, lo que empujaba a una espiral difícilmente solucionable, impidiendo al progresismo su retorno al juego parlamentario. Si el progresismo se declaraba en contra de la constitución vigente, su llamada al gobierno resultaba imposible; como no se permitía la entrada en el poder a los progresistas, estos desvelaban su intención de reimplantar la constitución de 1837 o la de 1856. De este modo, los recelos constituyentes de unionistas y moderados, como la estrategia del "todo o nada" adoptada por el grueso del progresismo, se convertían en las dos caras de una misma moneda, reflejo de la incapacidad de unos y otros de sustraerse a inercias, identidades y prejuicios que debían verse, a esas alturas, como extemporáneos. Lo que mostraba el rotundo fracaso de la estrategia conciliatoria que el unionismo había tratado de imponer desde hacía una década, incapaz de crear un mínimo clima de consenso sobre el que articular un nuevo sistema de partidos. De lo que unos y otros eran conscientes, y así obraron en consecuencia, es que tras los intentos conciliatorios, solo había camino para la revolución.

\section{NOTAS}

1 El presente artículo forma parte de una línea de investigación con artículos ya publicados, en los que se estudia, de forma comparada, la trayectoria del liberalismo peninsular desde 1851 hasta la antesala del Sexenio revolucionario (Chato, 2007, 2008, 2009a, 2009b, 2010, 2011a, 2011c).

2 Como Oliveira Martins vendría a sentenciar, la Regeneração portuguesa había supuesto "la transición de la era de las doctrinas para la edad de las conveniencias". (Martins, 1996, vol. II, p. 280). En enero de 1863 , al frente del nuevo gobierno tras la modificación ministerial, O’Donnell daba muestras de su escasa fe en las ideologías: <<no daré programa ninguno, aunque podría hacerlo, porque la moda de los programas ha pasado ya, atendido el poco resultado que producen $>>$. (Diario de Sesiones de Cortes [DSC], 19-1-1863, legislatura de 1863, t. I, p. 260).
Con respecto a la realidad revolucionaria previa a estos procesos de modernización política: (Bonifácio, 1992, p. 91134; 1999, pp. 133-181; 2002; 2009). Para el caso español: (Gil Novales, 2001, pp. 1-12); (Garrido Muro, 2002, pp. 2142); (Burdiel y Romeo, 2001, pp. 75-91).

3 Un estudio comparado de la evolución de los regímenes liberales en España y Portugal desde 1846 hasta 1863 en: (Chato, 2004; 2007, pp. 55-75; 2008, pp. 107-140; 2009a, pp. 125-158; 2009b, págs. 105-129; 2010).

4 En cuanto al significado de la Regeneração portuguesa: (Sardica, 2001, pp. 31-106; 2002, pp. 83-117).

En relación al proyecto unionista: (Durán de la Rúa, 1979). De especial interés es la comparación que establece en el epílogo entre la experiencia unionista y la Regeneração portuguesa, pp. 339349; (Martínez Gallego, 2001). Las intenciones transformadoras del sistema de partidos auspiciadas por la unión liberal en: (Chato, 2011a).

5 Acerca de la responsabilidad de la corona $y$, concretamente, de Isabel II en el funcionamiento del régimen liberal: (Burdiel, 2004, pp. 72-93; 2004, pp. 101-105); (Morales, 2004, pp. 63-74). En cuanto a la dinámica y caracterización de la monarquía constitucional a raíz del sobredimensionamiento de la corona: (Marcuello, 1986, pp. 283-376; 1988, pp. 15-36; 1987, pp. 197-236); (Garrido Muro, 2003, pp. 49-76); (Sánchez García. 2007, pp. 127-153). Con respecto a la definición de la nueva "monarquía constitucional de gobierno parlamentario" y la posición de la corona en el régimen liberal: (Lario, 1999, pp. 277-288; 2007, pp. 35-51; 2003, pp. 179-200). 
6 Además de otras reformas políticas y administrativas, la gran cuestión que supuso el desencuentro en las filas del unionismo fue el mantenimiento de la reforma constitucional del gobierno Narváez-Nocedal de 1857, que a pesar de mantenerse inaplicada a lo largo de los dos gabinetes presididos con posterioridad por O’Donnell, no llegó finalmente a abolirse. Aún, en enero de 1863, al objeto de evitar la salida de los unionistas disidentes, O'Donnell se veía obligado a manifestar su intención de derogarla: <<Hemos convenido en la necesidad de la reforma de la reforma constitucional; hemos convenido en la necesidad de dejar a los cuerpos colegisladores completa libertad para la formación de sus reglamentos, y hemos convenido también en la necesidad de respetar intereses creados en la otra Cámara>>. (DSC, 24-1-1863, L. 1862, t. I, p. 282). No obstante, volvería a incumplirla. Ríos Rosas había iniciado la lista de los disidentes en abril de 1861, engrosada, muy especialmente a finales de 1862, con la deserción de personajes de la talla de Alejandro Mon o Antonio Cánovas, o la del propio Prim a raíz de la cuestión de Méjico y los recelos generados entre las filas del unionismo. La formación del ministerio de enero de 1863, con la defenestración de Posada Herrera y la entrada de Pastor Díaz, cercano a los disidentes, no iba a lograr la resurrección de la unión liberal, frustrándose la pretendida "reconciliación". Ver al respecto las declaraciones en el Parlamento de Ríos Rosas (Francisco y Antonio), marqués de la Vega de Armijo, Vaamonde, Salaverría y Alonso Martínez, (DSC, 12, 13 y 14 de abril de 1863 , L. 1862, t. II).

En relación a la reforma constitucional de 1857: (Medina, 1975, pp. 75-105).

7 A pesar de que la opinión pública $-y$ la propia situación parlamentaria- era favorable a un gobierno de talante reformista, que avanzara en las tareas inconclusas del anterior gabinete, previendo la entrada de Ríos Rosas al frente de los disidentes, lo cierto es que Isabel II, más allá de sus naturales preferencias por el moderantismo, no tenía clara la solución que dar. De hecho, en sus miras iniciales estuvo la formación de un gobierno presidido por Mon-Armero o por el propio Narváez, elección ésta que provocó una destacable agitación social en Madrid. Tras valorar la formación de un nuevo gobierno de unión liberal, un gabinete de coalición y hasta la posible llamada de los progresistas al poder, se decidió finalmente por Mi- raflores, tomado como un gobierno de transición. Ver al respecto las intervenciones de Rivero y González Bravo en el Congreso: (DSC, 13 y 14 de abril de 1863, L. 1862 , t. II, pp. 524 y 566 respectivamente). Ver también Bermejo, 1872, vol. III, p. 585); (Miraflores, 1964, t. III, pp. 193-195).

8 (Miraflores, 1964, t. III, p. 205). El nuevo gobierno, sin identificarse como moderado, se definía dentro del campo conservador: <<Nuestra política será conservadora, constitucional, y tan liberal como aconseja la época y el siglo. Señores, hablar de retrogradar en el siglo del vapor y de la electricidad, es un verdadero anacronismo >>. El marqués de Miraflores no solo anunciaba la retirada de los proyectos legislativos presentados por el anterior gobierno, sino que se comprometía a dar una "solución definitiva" a la reforma constitucional de 1857: (DSC, 9-4-1863, L. 1862, t. II, pp. 492-493)

\section{9 (DSC, 12-4-1863, L. 1862, t. II, p. 531).}

10 (DSC, 14-4-1863, L. 1862, t. II, p. 566). Y añadía: <<El ensayo de la fusión ha salido mal, esa tentativa no ha producido resultado. [...\} Lo lógico es volver a lo que existía antes de que este ensayo se verificase. ¿Y qué existía? Existía la organización de dos grandes partidos, el antagonismo del partido moderado y de partido progresista>>. (Idem, p. 568).

11 (Capellán y Gómez de Ochoa, 2003, pp. 161-191).

12 Se quejaba González Bravo de esa caracterización sobredimensionada del moderantismo: <<es costumbre general considerar al partido moderado como un partido mera y exclusivamente de resistencia y de represión>>. (DSC, 144-1863, L. 1862 , t. II, p. 569).

13 (DSC, 15-4-1863, L. 1862, t. II, p. 579).

14 Denunciaba Calvo Asensio, refiriéndose a la política representada por Narváez: <<era un sistema inicuo de persecución y aniquilamiento contra el partido progresista: esto no era perseguir a los hombres que se habían levantado con las armas en la mano; era perseguir en masa a un partido a quien se quería extinguir, no solo para alejarlo del mando, sino para si esto no era posible, poder presentarle como anarquista y como incapaz de ser partido de gobierno, como incapaz de tener tranquilidad $>>$. (DSC, 15-4-1863, L. 1862 , t. II, p. 580). De hecho, ante la posible llamada a Narváez para la formación de un gobierno, en las calles de Madrid se produjo lo que Rivero vino a denominar "conmoción pacífica".

$15 \mathrm{El}$ partido moderado histórico, que mantuvo en el diario La España su principal exponente en la opinión pública, a pesar de sus divisiones y fragmentaciones, tomó como principal enemigo político a la unión liberal, considerando su existencia una verdadera amenaza para el sistema de partidos: <<La unión liberal como sistema fue una cruzada o una especie de somatén levantado contra los partidos moderado y progresista, como hecho fue una aventura política más afortunada que conveniente. [...] Incompatible con la existencia de los partidos progresista y moderado, de cuyos principios quiere alternativamente servirse para vincular en sí misma el motor en toda ocasión y en toda circunstancia: su mira inmediata, su empeño decidido es la destrucción y la muerte de los partidos legales que el organismo del sistema que nos rige están necesariamente llamados a alternar en el gobierno del país. [...] Sin dos partidos que se disputen el poder en el terreno legal, que se completen, por decirlo así, sirviéndose respectivamente de estímulo siendo el uno el censor del otro, no hay sistema constitucional propiamente dicho: atentar a la existencia de estos dos partidos es atentar a la verdad del sistema representativo. La unión liberal bajo este punto de vista es una amenaza contra el régimen constitucional>>. (La España, 27-3-1864).

16 Incluso después de optar por el retraimiento electoral, era éste el objetivo que los progresistas proyectaban: $<<$ Nosotros no combatimos ni podemos combatir la idea de la necesidad de un gran partido moderado que turne con el progresista en la dirección de los negocios públicos, en cuanto el sistema constitucional sea una verdad en nuestra patria >>. (La Iberia, 16-9-1863).

No obstante la negación que el progresismo hizo del unionismo, el propio O'Donnell habría tratado de que la unión liberal, y no el partido moderado, viniera a formar, junto a los progresistas, liderados éstos por el general Prim, el par de fuerzas políticas que vinieran a turnarse en el gobierno, englobando a los elementos liberal-conservadores del partido moderado. Ver al respecto la carta de Antonio Ma Campos a Ruiz Zorrilla, 11-12-1867, en (Álvarez Villamil y Llopis, 1929, pp. 90-92). De cualquier forma, los progresistas acogieron en 
un principio con cierta benevolencia la llegada de la unión liberal al gobierno, considerándola una transfiguración del moderantismo. Un nuevo partido que, siendo capaz de englobar las distintas fuerzas conservadoras, serviría para asentar definitivamente un sistema de partidos dual.

17 Durante la crisis ministerial, se había llegado a plantear, en los círculos de la reina, la posibilidad de llamar a los progresistas para formar gobierno, habiendo mantenido Isabel II una entrevista con Cortina y Madoz, en la que éstos, al parecer, aplazaban la oportunidad de un ministerio progresista. Los progresistas puros renegaron de Cortina y sus posibles declaraciones, desmintiendo lo que se decía por boca de Madoz: (La Iberia, 7-3-1863). Ver al respecto: (Millán García, 2001, pp. 103-107). Con posterioridad, el propio Miraflores se entrevistaría con Olózaga, al objeto de plantear el papel del progresismo como partido de oposición, paso previo a la formación de un futuro gobierno, siempre y cuando estuviera dispuesto a $<<$ renunciar a ciertas utopías >>. (Miraflores, 1962, pp. 208-209). La respuesta de los progresistas ante semejantes apostasías en (La Iberia, 1-4-1863 y 5-4-1863).

18 Las garantías dadas por el progresismo, al que había que reconocer un esfuerzo indudable creando una imagen de sí mismos aceptable, resultaron insuficientes para el grueso de moderados y el conjunto de fracciones conservadoras. Caído el unionismo, moderados y progresistas rompieron la $<<$ tregua de descanso, una especie de paréntesis en la política retrospectiva >>, que habían mantenido durante los últimos años, regresando a una dialéctica verbalmente violenta. El diputado Castro, en respuesta a los avisos de Calvo Asensio contra Narváez, atacaba al progresismo negando su apariencia conciliatoria y benevolente, subrayando su indeleble carácter revolucionario: <<¿dónde está la ley, dónde el código que os autoriza a esos motines continuos de que habéis vivido y de que por desgracia veo que no tenéis otro modo de vivir? ¡Y luego os quejáis! iY luego salen declamaciones, si no de vuestros bancos, de los que están más arriba! iY luego decís que estáis tradicionalmente desheredados! [...] No; lo que produce vuestro desheredamiento es vuestra historia>>. (DSC, 16-4-1863, L. 1862, t. II, p. 599).

19 En relación al reingreso de los "resellados" en el partido progresista: La Iberia,
20-3-1863. Acerca del significado del retorno de Prim: (Olivar Bertrand, 1975 pp. 366-373); (Anguera, 2003, pp. 393400). En cuanto a las ofertas lanzadas por O'Donnell y la propia Isabel II a Prim para una pronta entrada de los progresistas en el gobierno, ver la carta de Antonio Ma Campos a Ruiz Zorrilla de 11 de diciembre de 1867, en: (Álvarez Villamil y Llopis, 1929, pp. 90-92). En relación a los encuentros entre Isabel II y el conde de Reus: (Garrido, 1869, t. III, pp. 771-776)

20 (La lberia, 19, 23 y 26 de mayo de 1863). En cuanto a la crisis ministerial: (Miraflores, 1962, pp. 210-213).

21 Las circulares en cuestión fueron las de 13 y 20 de agosto de 1863: Gaceta de Madrid, 15-8-1863 y 21-8-1863, que además de hacer explícitas las intenciones del gobierno de ejercer las consabidas "influencias morales", establecían limitaciones a la hora de autorizar las reuniones electorales, reducidas exclusivamente al ámbito de los electores y bajo control de los gobernadores. Las referencias al "desheredamiento histórico" y a los "obstáculos tradicionales", síntesis del discurso victimista del progresismo, ya habían saltado a las pinas de "La Iberia" desde el mes de junio: ( $L a$ Iberia, 13-6-1863). Ver también: (Vilches, 2001, pp. 59-66); (Ollero, 2006, pp. 265-269); (Millán García, 2001, pp. 112-119). En cuanto al predominio de la vía revolucionaria en los progresistas y su significado político: (Romeo, 2003, pp. 296-314; 2006, pp. 105-113; 2007, pp. 69-88).

22 Esta opción era planteada, por primera vez, pocos días después de publicada la circular de 20 de agosto, a la espera de que los órganos del partido tomaran la oportuna decisión: (La Iberia, 30-81863). El centro progresista se reunió el 7 de septiembre en casa de Olózaga, aprobando el manifiesto en el que se decidía solicitar a los electores del partido su retirada de la contienda electoral. (La Iberia, 8-9-1863). "El manifiesto progresista 'A la nación'”, (La Discusión, 12-9-1863); también el artículo de víspera de las elecciones: "A los electores progresistas", (La Iberia, 10-10-1863).

23 (La Iberia, 9-9-1863).

$24<<$ El respeto a las leyes existentes es un deber, pero no su amor a ellas; pues si estas leyes, que respeta porque existen, son contrarias a su dogma político, con cuyas doctrinas ha gobernado al país y ha dado constituciones aceptadas por la misma corona, en este caso no debe contribuir activamente al sostenimiento de tal orden de cosas, sino combatirlo>>. (La Iberia, 30-9-1863).

25 Manifiesto "De los demócratas de Madrid a los de provincias", reproducido en La Iberia, 2-10-1863. Frente a La Discusión, órgano de expresión de Rivero, se apostaron, tras el diario El Pueblo, otros demócratas contra la conciliación con el partido progresista, al que consideraban "antirrevolucionario" y "retrógrado". La aparición de La Democracia, el 1 de enero de 1864, bajo la dirección de Castelar, trató de superar las divergencias en las filas demócratas, que se mantendrían sin lograr superarse. (Eiras, 1961), pp. 273-284); (Peyrou. 2008, pp. 463-472).

$26<$ Hoy, pues, debemos hacer caso omiso de la reforma de 1845 en nuestra discusión, que queda reducida por consiguiente a cuál constitución tomamos por bandera: si la de 1837 o la de 1856 . No teniendo nosotros noticia de ninguna derogación legal de la constitución de 1837 , creemos que esta es la legal, que es la que hoy debe considerarse subsistente, pues la de 1856 no llegó a promulgarse, aunque en las cortes constituyentes se convino en que todos sus artículos aprobados pudieran regir como leyes; y sosteniendo la legalidad de la constitución de 1837, como punto de partida para negar al poder ejecutivo la facultad de variar la forma fundamental del estado, queremos que se planteen los artículos aprobados, que lo son todos, de la constitución de 1856. La constitución de 1837 rige de derecho para nosotros, y queremos que rija de hecho la de 1856, mientras unas cortes constituyentes, cerrando de una vez el período constituyente, que sin ellas no puede cerrarse, no acaben de perfeccionarla >>. (La Iberia, 17-10-1863).

27 (La Iberia, 18-10-1863). O bien, y esto resultaba más difícil y complicado, que se convocasen elecciones con totales garantías para respetar la voluntad de los electores: $<<$ Si se quiere que el partido progresista venga al Congreso, disuélvanse esas cortes, que no debían haberse convocado; quítese la circular del día 20, dense garantías de libertad a los electores; olvídese la influencia moral; éntrese de buena fe en la práctica del gobierno representativo, y después hablaremos del asunto >>. (La Iberia, 20-11-1863). El retraimiento parlamentario no implicaba el dejar de participar en otras contiendas electorales. De hecho, los progresistas sí se presenta- 
ron a las elecciones municipales y de diputaciones provinciales del mes de noviembre, no así los demócratas, que permanecieron retraídos.

28 Con respecto a la posición ideológica y política del partido demócrata y su avance durante el gobierno largo de O’Donnell, así como la pervivencia de su vertiente carbonaria y conspirativa: (Peyrou, 2008, pp. 351-410). Ver también, en lo que se refiere a los movimientos de los demócratas exiliados en Portugal: (Chato, 2011b).

29 Tras el éxito parcial en las elecciones a diputaciones provinciales, los progresistas seguían resistiéndose, con expresivos remilgos, a la inercia revolucionaria hacia la que se encaminaban, con la tenue esperanza de ser todavía llamados a formar gobierno. Así venía a declararlo el propio Olózaga en un banquete en Madrid, celebrando el triunfo de sus acólitos en provincias. (La Iberia, 20-12-1863).

30 (Garrido, 1869, pp. 780-792). Los demócratas vieron con suma decepción la participación de los progresistas en las elecciones a ayuntamientos y diputaciones provinciales, provocando divergencias entre los que consideraban un apoyo a la causa revolucionaria su opción por el retraimiento y los que mantenían, como el propio Garrido, que el progresismo traicionaría el espíritu de la revolución. (Idem, pp. 798-817).

Los progresistas no dejaban de proclamar su monarquismo, su respeto a la dinastía y aun al régimen vigente: < Para nosotros sería una situación completamente nueva la de ocupar el poder llamados por la corona. Cuando esto suceda, cuando este día llegue, la Reina sabe que el partido progresista no es monárquico de conveniencia ni constitucional de farsa. El trono sabe que el partido progresista tiene en su divisa la palabra franqueza, en su bandera el lema dignidad, y en su historia toda borrada la palabra traición>>. (La Iberia, 15-1-1864). En el círculo más cercano de Isabel II, solo María Cristina defenderá con insistencia la formación de un gobierno con progresistas, influencia fácilmente neutralizada por la camarilla y otros allegados a la reina. (Garrido, 1869, pp. 869-870). Con respecto al ámbito cortesano y las influencias políticas en el entorno de Isabel II en esas fechas: (Burdiel, 2010, pp. 692-727). El punto de vista del progresismo acerca de la figu- ra de María Cristina en su regreso a España en: (La Iberia, 1-10-1864). Acerca del monarquismo del partido progresista: (Romeo, 2007).

\section{1 (DSC, 3-12-1863, L. 1863-1864, t. I, p. 283).}

En el proyecto de contestación al discurso de la corona, los unionistas Vega de Armijo y Posada Herrera habían expuesto en su voto particular su lamento por haber: <<cerrado, aunque sin quererlo acaso, las puertas de este cuerpo a uno de los partidos que han prestado a la libertad y al trono señalados servicios, y que obtiene por igual con todos, el aprecio y confianza de V. M.>>. (DSC, 1-12-1863, apéndice 3-4).

32 (DSC, 3-12-1863, L. 1863-1864, t. I, p. 276).

33 Más bien denunciara. (DSC, 25-4-1863, L. 1863, t. II, p. 767).

34 (DSC, 4-12-1863, L. 1863-1864, t. I, p. 306). Y añadía: <<La unión liberal no es más que una combinación parlamentaria; pero no es un partido político ni aquí ni fuera de aquí; y fuera de esta situación, quedan los partidos más avanzados ya en sentido progresista, ya en sentido retrógrado. [...] Esto no es más que la reunión de los centros que hay en todas las cámaras, $y$ esto se ha verificado cien veces en otros países, y estamos perdiendo lastimosamente el tiempo en inventar nombres que no sirven más que para confundir las ideas, [...] tiene su razón de ser, pero no es precisamente una cosa que esté vinculada en determinadas personas, en determinados ministerios, sino que agrupando los centros de los partidos, puede gobernar no solamente un ministerio, sino muchos ministerios $>$. (Ibidem, pp. 305-306).

35 (DSC, 15-12-1863, L. 1863-1864, t. l, p. 468).

36 (DSC, 11-12-1863, L. 1863-1864, t. I, p. 410). Acerca del significado político del "fusionismo" en la unión liberal: (Chato, 2010; 2011a).

$37<<[\ldots]$ de esa especie de puja que se ha establecido de a quién es más liberal; porque no parece sino que la diosa de la discordia ha arrojado a los partidos la manzana del poder con el lema "ial más liberal!" que todos se apresuran a recogerla con máscara de liberalismo. La verdad es que cada cual es y será lo que ha sido, diga lo que dijere >>. (DSC, 3-12-1863, L. 1863-1864, t. I, p. 276).
38 Así venía a caracterizar esta coyuntura política Idelfonso Bermejo: <<No Había remedio: todo ministerio liberal tenía que ser entonces forzosamente ministerio conciliador, ministerio de unión liberal; porque las divisiones y subdivisiones del liberalismo habían Ilegado a tal extremo, que no había fracciones compactas y numerosas para formar siquiera un gobierno con su indispensable cohorte de empleados políticos que pensase de un mismo modo. La conciliación fue condición indispensable a que cedió Narváez, como cedió a ella O’Donnell, como habría cedido Prim o el general Espartero〉>. (Bermejo, 1872, t. III, pp. 621-622).

39 Ver al respecto los discursos en las cortes del diputado Catalina $-<<$ España yace bajo la calamidad de un desconcierto político que está renovando en nuestra sociedad la catástrofe de la Babel antigua: $\{. .$.$] no parece sino que$ en los antiguos campos, donde antes se batían heroica y ordenadamente grandes partidos, [...] se ha dejado oír la voz siniestra de rompan filas, o el grito desconsolador de sálvese el que pueda, y que al majestuoso aparato de los ejércitos ha sucedido la deserción a la bandada o un miserable sistema de guerrillas $\gg .-$, defendiendo el voto particular de Nocedal, y de Silvela, proponiendo una línea liberal conservadora: $<<$ Yo entiendo que es indispensable la reorganización rigurosa del partido conservador liberal para realizar el sistema representativo, que consiste en que haya un partido representante de la idea innovadora y otro representante de la idea conservadora, [...]; es preciso digamos los conservadores liberales: no queremos amalgamas imposibles, pero tampoco queremos retroceder; [...] es preciso que el partido conservador liberal acepte la idea de que no ha de estacionarse en el poder con tal fuerza, que no pueda ser mañana desalojado de él sino por la misma fuerza. Es preciso aspirar a que llegue el día de que alternen pacíficamente en la esfera del gobierno los dos únicos grandes y legales partidos que pueden existir; es preciso que llegue el día de que reemplace la idea innovadora a la idea conservadora, sin necesidad de conmociones ni de pronunciamientos, sino por medios pacíficos y constitucionales $>>$. (DSC, 5-12-1863, L. 1863-1864, t. I, pp. 314 y 322 respectivamente). El propio conde de San Luis hacía defensa de la necesidad de los partidos históricos y de la vitalidad -desuniones aparte- del moderantismo, destacando la presencia de ese "principio liberal conciliador" en 
sus filas desde el inicio de su existencia: (DSC, sesiones ordinaria y extraordinaria del 26-12-1863, L. 1863-1864, t. I, pp. 626-636).

\section{0 (DSC, 15-12-1863, L. 1863-1864, t. I, p. 469)}

41 Bermejo explicaba el interés estratégico de O’Donnel por que la Reina llamase a Narváez a formar gobierno, al objeto de, vista la inconveniencia de una política reaccionaria y escasamente liberal, que de seguro pondría en práctica el duque de Valencia, facilitar su pronto regreso al poder. La cita proviene de una carta que Narváez dirigía a González Bravo, quien ocuparía la cartera de gobernación en los dos ministerios presididos por el general -de septiembre de 1864 a junio de 1865 y de julio de 1866 a mayo de 1868-. (Bermejo, 1872, t. III, pp. 603-604).

42 Ver al respecto el largo discurso de Nocedal y la réplica de Castro, que venía a calificar sus propuestas propias de <<un partido absolutista vergonzante, completamente fuera de la gestión de los negocios públicos. Eso no es partido conservador ni partido moderado en ninguna parte del mundo>>. (DSC, 7-12-1863, L. 1863-1864, t. I, p. 332-345 y 347-350 respectivamente).

43 Los diputados Moret y Barret presentaban sendas enmiendas al proyecto de respuesta al discurso de la corona, proponiendo incluir en el texto la necesidad de reintegrar a los progresistas dentro de la lucha legal, por medio de una nueva ley electoral que garantizara su presencia parlamentaria, la confirmación de los derechos políticos e individuales y la reforma de la constitución en sentido liberal. (DSC, 10-12-1863, L. 1863-1864, t. I, apéndices al $n \circ 28$ ).

44 (DSC, 18-12-1863, L. 1863-1864, t. I, p. 555).

45 Ver al respecto la intervención en el congreso del diputado barcelonés Barret, que explanaba una posición altamente comprensiva con el retraimiento progresista: (DSC, 19-12-1863, L. 18631864, t. I, pp. 573-577).

46 Así lo declaraba en las cortes: (DSC, 181-1864, L. 1863-1864, t. II, p. 744).

47 El propio Ulloa, diputado unionista, había planteado a las cortes la necesidad de asegurar la estabilidad constitucional: <<Mis amigos y yo creemos, y así lo declaramos solemnemente, que esa legalidad constitucional, que debe ser común a todos los partidos medios, sin la cual se agitarán en el vacío todos los conatos de resurrecciones históricas, no puede ser otra hoy sino la constitución de 1845 sin la reforma de 1857>>. (DSC, 26-2-1864, L. 1863-1864, t. II, pp. 1057-1058). Ese mismo día, el diputado Terrero presentaba una proposición <<derogando la reforma de 1857 y restableciendo la constitución de 1845 tal como fue promulgada>>, (DSC, 292-1864, L. 1863-1864, apéndice 1). El propio Mon declaraba que la constitución de 1845 constituía el <<símbolo común a todos los hombres de ideas monárquicas y liberales >>. (DSC, 2-31864 , L. $1863-1864$, t. II, p. 1085). Es cierto que incluía en su programa la aprobación de sendas leyes de imprenta y electoral, al objeto de hacerlas acordes con su objetivo de $<<$ desenvolver y aplicar en sentido liberal la constitución del estado >>.

48 El 22 de febrero de 1864, se reunían en la casa del director de El Clamor Público los directores de varios periódicos políticos, al objeto de redactar un manifiesto a favor de lo que denominaron "conciliación constitucional", estableciendo la constitución de 1845 -suprimida la reforma de 1857- como la norma básica común de los distintos partidos monárquico-constitucionales. A esta convocatoria se sumaron los directores de los diarios La Época, El Diario español, El Reino, El Contemporáneo, La verdad, El Eco del País, La Política, La Libertad, La razón Española y El Espíritu Público. (La Iberia, 24-2-1864).

En efecto, determinados progresistas, que se mantenían en estado de "resellamiento", entre los que destacaban Luzuriaga, Luxán y Santa Cruz, estaban dispuestos a aceptar la constitución de 1845 como base normativa, tomando como órgano de expresión a El Clamor Público. Ver al respecto las críticas que les dirigía el órgano de los progresistas puros: (La Iberia, 30-1-1864). El comité central del partido progresista, en una nueva circular, si bien era cauto a la hora de establecer la línea de acción ante una futura convocatoria electoral, fiel al dogma de la soberanía nacional, dejaba clara cuál era su postura desde el punto de vista constitucional: $<<$ ninguno de nosotros ha considerado ni puede considerar la constitución de 1845 como símbolo de sus creencias, ni siquiera como transacción entre los diversos partidos, porque no se hizo con semejante propósito >>. (La Iberia, 8-2-1864).
En cuanto a la supresión de la reforma de 1857: "Ley sancionada por S. M., y publicada en el Congreso, derogando la reforma de la constitución del estado verificada en 17 de julio de 1857", (DSC, 20-4-1864, apéndice 1 al no 106).

49 (La Iberia, 15-3-1864). Semanas después, volvía a incluirse en sus páginas una nueva advertencia: <<Para salir del caso en que estamos, no hay más alternativa que una revolución pacífica o una revolución material. La revolución pacífica de grandes resultados, sin que cueste una lágrima ni un trastorno, es la realización de nuestras ideas. Si la revolución pacífica es imposible, no hay que hacerse ilusiones, la revolución material se está palpando, y iay de todos si llega a estallar! > (La Iberia, 14-4-1864).

50 Y añadía: <<Lo dicho: dos años calculo que le queda de monopolizar el poder al partido moderado. A los dos años y un día la bandera progresista ondeará triunfante desde Cádiz a la Junquera, desde Badajoz a Irún. Brindemos, pues, amigos, y apuremos hasta la última gota, para que Dios haga verdad mi profecía >>. (La Iberia, 5-5-1854). En su discurso de cierre, Olózaga dejaba clara cuál era la postura de los progresistas con respecto al texto constitucional: $<<$ ¿podrá ser nuestra? Jamás habrá un progresista que reclame como símbolo suyo la constitución de 45. Digo más, señores: la constitución existente legalmente, según nuestros principios, es la constitución del año 37, porque nosotros hemos heredado los principios de los legisladores de Cádiz >>. Otras declaraciones pronunciadas por Olózaga en ese mitin, sirvieron para que se configurase la idea del desconcierto entre él y Espartero: $<<$ no creo, señores, ni que le falto, ni que le perjudico de ninguna manera el porvenir de mi partido, si digo que le creo sinceramente separado de todo propósito de gobernar por sí mismo la nación. No creo que tiene este deseo; no creo que le conviene, y yo declaro, con la lealtad de mi carácter, que tampoco le conviene al partido progresista ni a la nación>>. Las explicaciones a estas palabras, así como la respuesta dada por Espartero en ( $L a$ Iberia, 10-5-1864). El temor a posibles disensiones dentro del partido, llevó al comité central a redactar la circular de 16 de mayo para dar cierre a las pretendidas desavenencias entre los líderes progresistas: (La Iberia, 18-5-1864).

51 Desde los planteamientos del moderantismo, siempre se cuestionó el sincero dinastismo de los progresistas. Éstos se 
empeñaron en asegurar su fidelidad a Isabel II, tratando de apagar las infidelidades surgidas durante el Bienio, cuando se planteó la opción dinástica portuguesa para sustituir a los Borbones en España. Desde tiempo atrás, el iberismo venía encubriendo ciertas pretensiones dinásticas, que en esa coyuntura volvían a destaparse al calor de la deriva revolucionaria a la que se dirigía el partido progresista. Los recelos anti-iberistas aireados en la opinión pública portuguesa, servían para acusar al partido progresista de trabajar en planes insurreccionales tendentes a la unión ibérica. (La Iberia, 5-7-1864). Ver también la defensa frente a estas acusaciones, lanzadas desde diarios moderados como La España, en (La Iberia, 24-6-1864).

52 (La Iberia, 10-9-1864). Los progresistas jugaban con su calificación de revolucionarios, desvirtuando su significado y sus consecuencias: <<somos revolucionarios por naturaleza, lo somos por convicción, y cada día que pasa nos hacemos más revolucionarios; pero hoy, dada la situación de España, ¿quién no es revolucionario? ¿Quién no desea la revolución? La revolución, en el buen sentido de la palabra, es el cambio de lo existente. Cuando lo que hay es bueno, la revolución será mala; pero cuando lo que hay es malo, desear que se cambie, desear que lo reemplace otra cosa mejor, procurar que se acabe por todos los medios lícitos, es una cosa loable >. ( $\mathrm{La}$ Iberia, 27-8-1864).

53 Ver al respecto la justificación política dada por los progresistas: (La Iberia, 11, 13,14 y 15 de septiembre de 1864 ).

$54<<$ El campo electoral está abierto y patente; la ley que garantiza el derecho de entrar en él a cuantos tengan la capacidad necesaria para hacerlo, se cumple con rigor religioso, no hay opinión legítima que no pueda manifestarse, que no se manifieste en realidad con un desembarazo y un desahogo de que jamás se ha visto ejemplo en España; [...] ¿Qué más puede exigirse? ¿Qué más puede concederse? Si todavía quedan personas que se empeñen en resucitar sin razón, sin motivo y sin derecho el estado de tirantez anárquica y la agitación siniestra que hace poco tiempo se sienten, caiga sobre ellas la responsabilidad de las consecuencias a que semejante observación conduce $\gg$. Circular a los gobernadores sobre la convocatoria electoral, 14-10-1864, (Gaceta de Madrid, 15-10-1864).

55 Ante la nueva convocatoria electoral, el partido progresista, en su reunión del
Circo Price, renovó el comité central, encargado de adoptar la posición del partido ante las elecciones y marcar su línea de acción. (La Iberia, 18-10-1864). En los días siguientes, los miembros del comité discutieron acerca de la conveniencia de mantener el retraimiento, siendo éste aprobado por 65 votos a favor y solo 4 en contra. (La Iberia, 25, 26,27 y 28 de octubre de 1864).

56 "Manifiesto del comité central del partido progresista", 29-10-1864, (La Iberia, 3-11-1864).

$57<<$ El periodo electoral ha concluido, y con él cesan las circunstancias especiales que han inclinado el ánimo del gobierno de S. M. a dejar completamente libre y entregada a sí misma la acción de la prensa periódica. El gobierno ha querido que mientras durase le movimiento de la lucha se manifestaran todas las opiniones, hasta las más extremadas y violentas [...]. Ha pasado, pues, la época de transición; [...] hora es por consiguiente de que el poder gubernativo recobre la plenitud de la fuerza que de consumo le otorgan la confianza de S. M: el apoyo probable de la nación legítimamente representada y la protección tutelar de las leyes $>$. Circular del ministerio de la gobernación, 25-11-1864, (Gaceta de Madrid, 26-11-1864). La respuesta del progresismo a este viraje en (La Iberia, 27-11-1864). Aunque hubo moderados y unionistas que alentaron la liberalización del régimen para conseguir el fin del retraimiento progresista, muy especialmente por medio de una nueva ley electoral que facilitara su presencia en el parlamento, una corriente importante del moderantismo exigía una política de mayor dureza frente a demócratas y aun progresistas. Más aún los que, como Nocedal, se encontraban en el extremo más conservador: $<$ el partido progresista es un partido revolucionario, el partido progresista se ha colocado fuera de la ley, el partido progresista no puede turnar con vosotros en el mando, el partido progresista no os puede dar juego en ese juego de las instituciones >. (DSC, 22-2-1865, L. 1864-1865, t. I, p. 651).

58 El banquete de la "Fonda Española", celebrado en Madrid el 5 de marzo, en el que participaron, al alimón, líderes de los partidos progresista y demócrata, confirmaba la apuesta revolucionaria del progresismo y la unión de miras de ambos partidos. (La Iberia, 7 y 9 de marzo de 1865). Esta unión estratégica sería criticada por los demócratas de La Discusión.
59 (DSC, 25-2-1865, L. 1864-1865, t. II, p. 712). Los sucesos de la Noche de San Daniel llevaron a buena parte de los moderados a cerrar filas en torno a la labor del gobierno, incluidas las medidas represivas adoptadas, dando por zanjada toda medida contemplativa para con los progresistas.

60 Ver al respecto el anuncio de O’Donnell al comunicar a las cortes la política del nuevo gobierno: (DSC, 22-6-1865, L. 1864-1865, t. V, p. 2878). El nuevo proyecto de ley electoral en (idem, Apéndice 10 al $n$ ㅇ 114). En cuanto a la nueva ley electoral propuesta por el gobierno, ver las críticas del moderantismo a la política concesiva auspiciada por la unión liberal: (DSC, 3-7-1865, L. 1864-4865, t. V, pp. 2997 y 3004$).$

61 Los progresistas lamentaban que en el nuevo gobierno no apareciese la única figura que, a sus ojos, conservaba una mínima honestidad y coherencia con la línea reformista y verdaderamente liberal del proyecto unionista: Ríos Rosas. La presencia de Posada Herrera en gobernación la interpretaban como la repetición de la política escéptica y estéril de los pasados gobiernos unionistas. ( $L a$ Iberia, 24-6-1865). La postura resistente del progresismo ante la aparente política concesiva de la unión liberal en: ( $L a$ Iberia, 5-7-1865).

62 A pesar de la postura firme que mantuvo La Iberia, órgano tradicional del progresismo puro, importantes personalidades del partido defendieron la oportunidad de salir del retraimiento que el nuevo ministerio les brindaba ante la nueva convocatoria de elecciones a cortes. De hecho, el comité central volvió a discutir la posición a adoptar ante los nuevos ofrecimientos del ministerio y las posibilidades que pudieran desprenderse de la nueva ley electoral. Discutida la cuestión, votaron a favor del retraimiento 71 miembros del comité, con solo 12 votos en contra, que fue la opinión de Santín de Quevedo, Prim, Madoz, Mendoza, Ruiz ZorriIla, Borrell, Mosquera, Bautista Alonso, González de la Vega, Ugarte, Pedro Mata y Gaminde. (La Iberia, 16 y 17 de noviembre de 1865). <<El partido progresista no debe salir del retraimiento. De pie todavía la influencia teocrática en las altas regiones del gobierno, la situación es hoy, lo que era ayer, lo que ha sido siempre, lo que será mañana, ínterin no se varíen radicalmente los fundamentos políticos en que se apoya. la nueva ley electoral es una concesión, pero concesión que, en el ejercicio de la 
ley, se convertirá en sarcasmo >. "Manifiesto a la nación", 20-11-1865, (La Iberia, 26-11-1865).

63 El concepto de "fusão" aparece en el lenguaje político parlamentario a raíz de la Convención de Évora Monte, al objeto de reintegrar al miguelismo dentro del triunfante régimen liberal. Años después, tras la Convención de Gramido, que ponía fin a la Patuleia, reaparecía nuevamente este término, tratando de reintegrar en una misma legalidad a setembristas y cartistas. En uno y otro caso, el uso que se hacía de la fusión tenía que ver con el ánimo de concordia, conciliación y hasta de perdón de dos bandos que habían llegado a un enfrentamiento bélico directo $y$ abierto. En sentido estricto, se emplea el término "fusionismo" para referirse a los gobiernos de coalición (históricos y regeneradores) que tienen lugar a partir del primer gobierno presidido por Aguiar en septiembre de 1865.

64 Ver al respecto: (Bonifácio, 1992; 2009).

65 Acerca de la esterilidad política de este último gobierno: (Bonifácio, 2001).

66 En relación a los "Sucesos de Natal": (Palacios, 2008, pp. 100-105).

67 Acerca del "avilismo": (Sardica, 2004 pp. 71-79) y, con lo que atañe a su participación en los gobiernos históricos, (idem, pp. 339-382).

$68<<$ El ministerio, apoyado en el elemento más avanzado del partido histórico y por consiguiente en las sociedades cuasi revolucionarias que más de una vez impusieron su voluntad al actual presidente del consejo, no perdona, sin embargo, medio alguno para recuperar la confianza y el apoyo de los diputados disidentes que se separaron de su política al ver al Sr. de Ávila alejado de los consejos de la corona; hasta aquí todos los esfuerzos hechos para lograr una reconciliación entre ambas fracciones del partido dominante se estrellan más en las antipatías personales de sus jefes que en el antagonismo de principios políticos $>>$. (Despacho del Ministro de España en Lisboa al Ministro de Estado [Des. del MEL al ME], 28-3-1862, Archivo del Ministerio de Asuntos Exteriores [AMAE], Correspondencia de embajadas y legaciones [Portugal], legajo H-1692). -El jefe de la legación española era, en esa coyuntura, el marqués de la Ribera-.

69 La cuestión de las Hermanas de la Caridad había supuesto su principal es- cenario de confrontación, planteando siempre medidas más drásticas que las que Loulé se veía obligado a adoptar. (Bonifácio, 1999b). La solución definitiva a este conflicto la sirvió el propio monarca, que solicitó la intervención de Napoleón III para que embarcase destino a Francia a las monjas francesas. (Des. del MEL al ME, 31-5-1862 y 10-61862, AMAE, leg. H-1692).

70 <<Por lo demás, la cuestión de los acontecimientos del 25 y 26 del mes próximo pasado ha perdido su importancia, desde que se sobreseyó en las causas formadas a los jefes del movimiento y desde que todos los presos fueron puestos en libertad. Esta lenidad por parte del Gobierno se interpreta por sus amigos como un deseo de legar al olvido tan lamentables ocurrencias, y por sus adversarios se atribuye a una amenaza hecha al presidente del consejo de ministros, por los individuos pertenecientes a la Asociación Patriótica encarcelados, de publicar la correspondencia de dicho señor que pone de manifiesto el acuerdo que siempre ha reinado entre el jefe del gabinete y una sociedad revolucionaria que llegó a discutir el regicidio en una de sus turbulentas sesiones $>>$. (Des. del MEL al ME, 31-1-1862, AMAE, legajo $\mathrm{H}-1692$ ).

71 Loulé apenas disponía de una mínima ventaja en el parlamento, encontrándose en minoría en la cámara de los pares, obteniendo de D. Luis, como había recibido de Pedro $\mathrm{V}$ antes de su muerte, una nueva remesa de pares adictos. (Des. del MEL al ME, 30-12-1862, AMAE, leg. H-1692)

72 La radicalísima ley de enseñanza, que llegó a ser aprobada en el parlamento y que se quería fuera el emblema político del nuevo gobierno, subió a la cámara de los pares, en donde quedó derrumbada sin que nadie llegara a protestar. Incluso los propios radicales sabían que era extremada de más

73 Fue María Pía de Saboya la elegida como esposa del rey Luis I, una opción que satisfacía las aspiraciones de los radicales por el carácter marcadamente progresista y liberal encarnado en esta dinastía. <<El partido portugués más avanzado que simpatiza con el de la unidad italiana, apoya el matrimonio con esta princesa y trabaja cuanto puede para conseguirlo $>$. (Des. del MEL al $M E$, 16-6-1862, AMAE, legajo H-1692). También los despachos de 11 de julio y 11 de agosto de 1862, en los que daba cuenta de las reacciones alarmantes de la prensa española ante este casamiento y las respuestas en la opinión pública portuguesa. (Ibidem).

74 (Catroga, 2000, pp. 12-13). Además del frente secularizador, que el radicalismo abrió en torno a la cuestión de las Hermanas de la Caridad, los radicales harían también uso del nacionalismo, como elemento principal de su identidad política. De hecho, por medio de la Asociación Primero de Diciembre, fundada años antes, trataron de capitalizar el sentimiento nacional, aprovechándose del protagonismo que representaba la cuestión ibérica y el anti-iberismo en la opinión pública portuguesa. La primera celebración popular que capitanearon, aplazada la primera convocatoria por coincidir con la muerte de Pedro V, tuvo lugar el 1 de diciembre de 1862. (Des. del MEL al ME, 17-11-1862, 26-11-1862 y 2-12-1862, AMAE, legajo $\mathrm{H}-1692$ ). En esta tarea de establecer una nueva ética cívica participaban, no obstante, otras fuerzas políticas del liberalismo portugués, a modo de proyecto compartido, lo que permitía al radicalismo liderar un proceso que contaba con la aprobación de históricos y aun regeneradores.

75 (Des. del MEL al ME, 31-3-1861, AMAE, legajo $\mathrm{H}-1692$ ).

76 (Espinha da Silveira y Fernandes, 2006, p. 137). Desde hacía tiempo, se identificaba a Saldanha con la posibilidad de encabezar un golpe militar, lo que mantenía alerta a Loulé, quien pretendía sacar de la actualidad política al Mariscal por medio de un cargo diplomático. $<<(\ldots)$ de las insignificantes manifestaciones hechas pocos meses hace, tanto en las provincias como en esta corte a favor de la vuelta al poder del mariscal Saldanha. Desde entonces ha venido tomando incremento esta idea en la opinión pública, y alarmado el Gobierno por algunas proclamas sediciosas repartidas en los cuarteles y otros manejos destinados a poner en evidencia al Mariscal, a quien con razón o sin ella, se atribuyen aspiraciones de mando $>$. Ya entonces, Loulé había pretendido alejar a Saldanha de Lisboa, intentando enviarle de embajador extraordinario en Italia. (Des. del MEL al ME, 30-6-1861, AMAE, legajo H.1692)

77 (Bonifácio, 2007, pp. 273-274). Saldanha hacía publicar una carta dirigida a Loulé en la que se exculpaba de los rumores que le hacían partícipe de complots contra el gobierno, asegurando la tranquilidad y fidelidad del ejército, pero declarándose activo ante una po- 
sible intervención. <<La contemplación del cuadro melancólico en el que se me figuran diseñados nuestro presente y futuro, no podía dejarme indiferente; y meditando profundamente qué línea de conducta me incumbe seguir en circunstancias tan melindrosas, mi conciencia me impuso el penoso deber de, sin ir al encuentro del poder que me repugna, no eximirme pertinazmente al servicio de la causa pública, cuando ella de mí exija el mayor de los sacrificios. $Y$ cuando instado por muchos hombres serios, y de todas las opiniones para volver a las lides políticas, les he declarado que si el Rey, nuestro buen amo, alguna vez resolviese encargarme de la formación del ministerio, por juzgar que mis servicios aún puedan concurrir para e esplendor de su trono, para la conservación de la independencia nacional y para la consolidación de las públicas libertades, yo no recusaría, por difíciles que fueran las circunstancias, sin de modo alguno apresar por cualquier acto ni un cambio ministerial, que juzgo de mayor conveniencia, sea solo el resultado de las condiciones propias de los gobiernos representativos $>$. Publicado en (A Opinião, 21-6-1861).

78 (Des. del MEL al ME, 2-11-1862, AMAE, legajo $\mathrm{H}-1692$ ).

79 (Palacio Cerezales, 2008, pp. 113-126).

80 "Programa de un nuevo partido". José Estevão y los redactores de los diarios Política Liberal, Jornal do Commercio, Portugués y A Libertade firmaron este programa, al que se adhirieron. En nombre de estos periódicos firmaron el documento Manuel Tomás Lisboa, José María Latino Coelho, Manuel de Jesús Coelho, João Félix Rodrigues, José da Silva Mendes Leal Júnior, Luis Augusto Rebelo da Silva, Jacinto Augusto Freitas Oliveira, José Elias García, Mariano Ghira y Gilberto António Roia Júnior. En él se trataba de superar los presupuestos políticos que habían conformado el nuevo régimen político y restablecer la pugna política, adormecida en los últimos años: <<Es preciso cuanto antes parar en estas concesiones mutuas, en estas complacencias habituales. Es urgente, sin odios ni ruines tensiones, consultarse los hombres públicos y reconstruirse los gremios políticos, no para retomar todas las aspiraciones y prácticas de las que el tiempo ya hizo la debida crítica, sino para restablecer la escrupulosidad doctrinal, que es la guarda de la conciencia de los individuos y de las multitudes [...]. Acabar con los partidos es una utopía seductora que, a ser posible, importaba una revolución en el vivir actual de los hombres y de las naciones, pasando la humanidad a una existencia que por ventura no sería la más digna ni la más feliz. Barajados, amalgamados, prender sus ideas opuestas en los lazos de una conveniencia misteriosa, encontrar la acción de unos con la acción de los otros y enseñarles por únicos dogmas la paciencia y la sujeción es arruinar toda la actividad social e imponer a la conciencia pública un sacrificio del que el sistema representativo no solo no carece, sino con el que es del todo punto incompatible>>. (Estevão, 1962, pp. 222-226).

81 (Diario de la Cámara de los Diputados de Portugal [DCD], 29-1-1862, p. 329).

$82<<$ El lema de los partidos fue por largo tiempo la intolerancia política; ¿quién hay hoy que la sustente? Fue la divergencia en las altas teorías de la constitución política; fue eso lo que hizo por veces sustituir una ley fundamental por otra. No obstante, esas cuestiones interminables, esas cuestiones que costaron mucha sangre acabaron todas por el acto adicional y acabaron principalmente porque el país estaba cansado y estimó hallar aquel medio, que sirvió como de arco de paz para terminar esas cuestiones. No es porque el acto adicional mezclase todas las ideas políticas de la antigua situación política; debo decir con franqueza que no satisfizo todas; pero satisfizo las ideas más importantes, y los partidos políticos, cansados de luchas, entendieron que era tiempo de dejar al país bajo la idea de una amplia libertad y de una gran tolerancia >>. Ibidem, p. 330.

83 Acerca de la figura de José Estevão y su proyecto de formar un gran partido verdaderamente liberal, así como su actuación política en la última fase de su vida: (Freitas Oliveira, 1863. pp. 345-407).

84 El diputado regenerador Casal Ribero hacía énfasis en el exceso de versatilidad de Loulé y su afán por mantenerse en un cargo que, ya entonces, resultaba demasiado prolongada: <<Es preciso que nos entendamos; nadie, absolutamente nadie, tiene el monopolio de la gobernación; la doctrina se hizo para todos, esto no admite excepciones. No se puede gobernar siempre con todos los compañeros y con todas las ideas. No se puede ser presidente del consejo hoy con el sr. António José d'Avila en nombre de la fusión política, y mañana con el sr. Lobo d'Avila y el sr. Mendes Leal en nombre del exclusivismos po- lítico. [...] En el sistema constitucional hay un rey, pero hay un rey, iuno solo! [...] El rey queda siempre, los ministros mudan con las necesidades variables de la política; el rey es permanente y los ministros inestables; el rey es inviolable, todos lo acatan, está por encima de los partidos, los ministros discuten y son discutibles. Esta es la belleza del sistema constitucional; esta es su fuerza y su acción >>. (DCD, 17-5-1862, p. 1227). Los nuevos ministros nombrados fueron João Crisóstomo de Abreu e Sousa y el general Ferreira Passos, célebre a raíz de su acción al frente de la represión del levantamiento de "María Bernarda".

85 El representante español, marqués de la Ribera, trasladaba al gobierno español las críticas lanzadas por los líderes regeneradores, que acusaban a Loulé de atentar $<<a$ las buenas doctrinas constitucionales, y ver en el presidente del consejo una especie de entidad aparte con fueros especiales superiores a las reglas comunes y a los deberes de compañerismo para con sus colegas [...] que siendo presidente de un gabinete se reconstituyese éste quedando el jefe del anterior, jefe también de nuevo>>. La discusión parlamentaria derivó en ciertas inconveniencias diplomáticas, al referirse el diputado regenerador Serpa Pimentel, caracterizando la situación política española, a la preponderancia de la "camarilla" y, muy especialmente, a la influencia de sor Patrocinio. (Des. del MEL al ME, 29-1-1863, AMAE, legajo H-1693).

86 (Des. del MEL al ME, 21-5-1863, AMAE, legajo $\mathrm{H}-1693)$.

87 Los centros y clubes políticos, al igual que las propias logias masónicas, intensamente politizadas, cobraron un especial protagonismo en esta coyuntura. Latino Coelho lideraba el centro del Patio do Salema, el conocido como "Clube dos Lunáticos". Por otra parte, Lobo d'Ávila, máximo representante de la "unha preta" tras la muerte de José Estevão, se convertía en el Gran Maestre de la Confederación Masónica Portuguesa, de la que se vendría a escindir, fundando la Confederación Masónica Progresista de Portugal. Tiempo antes, Elías García, representante de una línea claramente republicana, había formado la Federación Masónica Portuguesa. (Oliveira Marques, 1996, vol. II, pp. 103112).

88 Como indicaba el representante español en Lisboa, Loulé pretendía continuar, más allá de las dificultades y 
defecciones, al frente del gobierno, contando con el inquebrantable apoyo de Luis I y gracias a los principios conciliatorios de los que la oposición también comulgaba: <<No ejerciendo la imprenta todo el legítimo predominio que debiera sobre la opinión pública y careciendo la oposición de influencia en palacio, el duque de Loulé se promete seguir por largo tiempo al frente del gobierno, tanto más cuanto que los jefes de la oposición no parecen dispuestos a apelar a medios ilegales para disputarle o alejarle del poder y porque no es imposible que en un día dado se realice una fusión con esos mismos jefes $>$. El motivo de los ataques contra Lobo d'Ávila venían de la cuestión de la "cruz de Soutulho", un asunto turbio, asesinato incluido, que involucraba al ministro en la concesión de medallas a cambio de la asignación de una herencia. (Des. del MEL al ME, 20-8-1864, AMAE, legajo $\mathrm{H}-1693)$.

$89<<$ Se ha hecho patente la poca armonía que reina entre las dos parcialidades en que se dividen los diputados que apoyan la política del ministerio y que es una consecuencia del dualismo que hace tiempo viene trabajando a aquél. [...]Esta divergencia en la mayoría crea una situación indefinible. Todos los días corren rumores de una modificación ministerial, que luego se desmienten, y sin embargo se espera que en breve tenga lugar $>$. El marqués de la Ribera explanaba la intención antigua de Loulé de librarse de Lobo d'Ávila, considerado entonces un incómodo socio del que el gobierno debía prescindir. Por otra parte, informaba de la resistencia de éste a abandonar el ministerio, buscando la crisis completa del gobierno y no la simple modificación ministerial que buscaba Loulé, para conseguir mantener la situación bajo su mando. (Des. del MEL al ME, 31-1-1865, AMAE, legajo $\mathrm{H}-1693)$.

$90<<$ Su solución definitiva viene prolongándola por el estado de disolución en que está aquí todos los partidos, y por la situación especialísima que ocupa e duque de Loulé. Enlazado a la familia real, disfrutando del prestigio e influencia que le dan su alta posición social y su carácter, en lo general respetado, parece ser hace mucho tiempo la base casi forzosa de todo ministerio, alterando esto en cierta manera las condiciones esenciales del régimen parlamentario y constitucional. [...] Sus adversarios, desesperando de derribarlo, han intentado más de una vez atraérselo, y la lucha existente todavía para organizar bajo su presidencia un ministerio de fusión o para modificar sencillamente el actual dentro del partido setembrista histórico, es lo que da principalmente origen a la prolongación de la presente crisis. Ha llegado ya, sin embargo, el momento en que su solución no puede demorarse >. (Des. del MEL -Diego Coello y Quesada- al ME, 24-2-1865, AMAE, legajo $\mathrm{H}-1693)$. Aunque Loulé presentó su dimisión al monarca, éste volvió a encomendar al duque la formación de un nuevo ministerio, dado que ni el conde de Torres Novas -embajador de Portugal en la India-, ni el presidente de la cámara de los pares, el conde de Castro, ni Sá da Bandeira habían sido capaces, faltos de todo resorte político con el que poder contar con un apoyo mínimo, de aceptar este encargo. Las críticas al nuevo gobierno no solo vinieron de la oposición, sino también desde la mayoría, desunida desde la última crisis ministerial. <<Los ataques han sido vivos considerando como inconstitucional la crisis, personalizándolos en el duque de Loulé, a quien se acusa de querer fundar un poder irresponsable y dirigiéndose alguna alusión intencionada a personas más altas todavía >>. (Des. del MEL al ME, 6-3-1865, AMAE, legajo $\mathrm{H}-1693$ ).

91 (Des. del MEL al ME, 18-3-1865, AMAE, legajo $\mathrm{H}-1693)$. El representante español se atrevía a vaticinar el futuro político inmediato, acertando a adivinar bien un próximo gobierno de "fusión" bien un ministerio centrado en la figura de Saldanha: <<Disuelto el antiguo partido cartista o conservador, profundamente dividido, más por cuestiones de personas que de ideas, el progresista histórico, sin un jefe reconocido después de la marcha de Saldanha, el de los regeneradores, a cuyo lado están hoy los hombres más conservadores, el poder fluctuará entre ministerios o impotentes o de fusión. Dudo que el actual, si el parlamento sigue abierto, pueda continuar largo tiempo como está constituido, y siendo difícil una cuarta reorganización, no me sorprendería que el mariscal Saldanha, cuyo regreso se anuncia, fuese llamado en un periodo no lejano a constituir con los condes de Torres Novas y d'Avila y tal vez con Fontes y Casal Riveiro, una nueva situación>>. (Idem).

$92<<$ Su objeto era reconciliar los dos matices del partido progresista histórico dando para ello entrada en el Gabinete a los condes d'Avila y de Torres Novas y a los Señores Braamcamp y Luciano de Castro. Hasta este momento las tentativas con este objeto no han te- nido resultado. Es difícil presagiar el desenlace de la crisis pero me parece probable que su solución sea un ministerio de fusión presidido por el Conde d'Avila>>. (Des. del MEL al ME, 12-41865, AMAE, legajo H-1693).

$93<$ No habiendo dado feliz éxito las negociaciones entabladas para una fusión entre el partido progresista histórico y los llamados regeneradores que se negaban a formar parte de un gabinete presidido por el general Sa da Bandeira, aunque están dispuestos a entrar con el conde d'Ávila, el ministerio se ha constituido con los disidentes de la mayoría de una y otra Cámara, pero sin que la facción más numerosa que apoyó al duque de Loulé esté representada en la nueva administración >>. (Des. del MEL al ME, 18-4-1865, AMAE, legajo H-1693).

94 (DCD, 6-3-1865), (Vieira de Castro, 1866, pp. 23-32). En relación a esta peculiar figura y su situación al margen de los partidos histórico y regenerador: (Valente, 2001, pp. 154-194). Una perspectiva en la que coincidía, observador aventajado, el ministro de España en Lisboa: <<Ninguna diferencia de ideas en materias políticas, ni aún en las económicas, divide realmente a los diversos grupos parlamentarios que tienen verdadera influencia en las cortes. El genuino partido cartista o conservador, que tal vez tendría una política distinta que aplicar a la gobernación del estado, especialmente alejado de la influencia, así en las regiones de palacio, como en las del parlamento. Regeneradores, progresistas históricos y disidentes de la mayoría luchan por cuestiones de personas y por rivalidades del poder, pero sería bien difícil adivinar en qué soluciones difieren radicalmente los duques de Loulé y de Saldanha, Fontes y Lobo d'Ávila, Casal Ribeiro y Sá da Bandeira. Todos proclaman una política progresiva no solo en el interior, sino en las cuestiones que se agitan en Europa>>. (Des. del MEL al ME, 18-4-1865, AMAE, legajo $\mathrm{H}-1693)$.

95 La situación reunía todos los ingredientes para convertirla en revolucionaria: $<<$ En otro cualquiera país, donde hubiese ocurrido esta grave serie de hechos anómalos o habría una gran excitación pública, o se estaría en vísperas de la revolución o de una dictadura. Aquí sea carácter del pueblo portugués, sea cansancio o indiferencia pública, en la superficie al menos, no se ven síntomas de agitación; pero como todo lo que es anormal produce al fin desastrosos 
frutos, yo no extrañaría que a la larga esta situación los diera fatales, sobre todo, si coincide con sucesos graves en España o en alguna nación de Europa. De todas suertes, un país tan tranquilo como éste, la carencia de gobierno y el espectáculo a que estamos asistiendo enflaquece el principio de autoridad, hace imposible la administración y menoscabe el prestigio del régimen constitucional >> (Ibidem).

96 (Des. del MEL al ME, 30-4-1865, AMAE, legajo H-1693).

97 Los estados mayores de ambos partidos formaron un centro electoral, que definieron como "progresista", encargado de elaborar el "manifiesto de la 'fusión'”, en el que defendían los mismos principios que dieron nacimiento a la Regeneração, poniendo especial énfasis en las mejoras materiales que caracterizó la política "fontista" del primer gobierno regenerador. Desde el punto de vista político, salvo la proposición de fusionar ambos partidos, no planteaba ningún avance ni reforma sobre los fundamentos establecidos en la Carta y el Acta adicional, manteniendo, por tanto, los mismos principios que definían el sistema político vigente sin introducir modificación ninguna, contrariando las demandas de las fuerzas radicales. Las elecciones de julio de 1865 resultaron ser una de esas convocatorias especiales y anormales en las que el gobierno, obteniendo una mínima mayoría, no aseguraba su predominio en el parlamento, dado el número abultado de diputados de la oposición. Es cierto que las distintas corrientes que venían a apoyar al gobierno no fueron capaces de afrontar, con una mínima unidad y coherencia, las elecciones. Con respecto a las elecciones en el Portugal del ochocientos: (Tavares de Almeida, 1991); (Bonifácio, 2007b).

98 (Des. del MEL al ME, 30-4-1865, AMAE, legajo H-1693).

99 (Carnota, 1880, vol. II, pp. 364-368). E entonces representante español en Lisboa, Méndez de Vigo, daba cuenta de las conversaciones existentes entre Sá y el propio monarca con Saldanha, así como la negativa de éste de aceptar la jefatura del gobierno que se le ofrecía, Mostrándose dispuesto, sin embargo, a formar un gobierno propio. D. Luis no aceptaría las condiciones del general, opuesto a un cambio completo de ministerio y a una próxima disolución de las cortes. (Des. del MEL al ME, 30-71865, AMAE, legajo H-1693).

100 A pesar de haber llamado expresamente al conde de Lavradio, que ejercía la jefatura de la legación portuguesa en
Londres, y aun de haberse comprometido con Saldanha para sustituir a Sá da Bandeira, Juan Comyn, recién nombrado representante en Portugal, informaba de que ni uno ni otro habían sido consultados por el monarca. En ese mismo despacho destacaba, dentro del elenco ministerial, la figura de Fontes. (Des. del MEL al ME, 5-9-1865 AMAE, legajo $\mathrm{H}-1693$ ).

101 Ver al respecto: (Doria, 2004), (Guimarães da Cunha, 2003).

102 Acerca del movimiento de intelectuales y políticos radicales en busca de una nueva expresión ideológica y organizativa: (Ramos, 1992).

103 Sobre esta coyuntura política, la más valiosa aportación ha sido la de Vasco Pulido Valente: "Dores de crescimento (1864-1871)", un working paper que no llegó a salir a la luz de la edición, que presentó al seminario "Portugal moderno, 1834-1934" del Instituto de Ciências Sociais de Lisboa, en el período de 1988-1990, especialmente los dos primeros capítulos: 'O fim de uma era (1864-1865)' y 'A concordia universal (1865-1867)'. Agradezco a la profesora Fátima Bonifácio el haberme facilitado este texto.

\section{BIBLIOGRAFÍA}

Álvarez Villamil, V. y Llopis, Rodolfo (1929): Cartas de conspiradores. La revolución de septiembre, de la emigración al poder, Madrid, Espasa-Calpe.

Anguera, Pere, (2003): El general Prim. Biografía de un conspirador, Barcelona, Edhasa.

Bermejo, Ildefonso, (1872): La estafeta de palacio. Cartas trascendentales dedicadas a S. A. R. el Príncipe D. Alfonso de Borbón, Madrid, Imprenta de R. Labajos.

Bonifácio, Mạ Fátima (1992) “«A guerra de todos contra todos» (ensaio sobre a instabilidade política antes da Regeneração)", Lisboa, Análise Social, no 115, Instituto de Ciéncias Sociais.

Bonifácio, Mạ Fátima (1999a) "O século XIX em perspectiva política (1807-1890)", en Apologia da história política. Estudos sobre o século XIX portugués, Lisboa, Quetzal Editores.
Bonifácio, Ma Fátima (1999b) “A republicanização da monarquía (1858-1862)" en Apologia da história política. Estudos sobre o século XIX portugués, Lisboa, Quetzal Editores.

Bonifácio, Ma Fátima (2001) “História de um nado-morto: o primeiro ministério histórico (1856-59)". Análise Social, no 157, Lisboa, Instituto de Ciéncias Sociais.

Bonifácio, Mạ Fátima (2002) A segunda ascensão e queda de Costa Cabral (1847-1851), Lisboa, Imprensa de Ciências Sociais.

Bonifácio, Mạ Fátima (2007a) "Saldanha: uma vida feliz", en Estudos de história contemporânea de Portugal, Lisboa, Imprensa de Ciências Sociais.

Bonifácio, Mạ Fátima (2007b) "O maior patrono de Portugal (Problemas em torno das eleições oitocentistas (1852-1884)", en Estudos de História Contemporânea de Portugal, Lisboa, Imprensa de Ciências Sociais.
Bonifácio, Ma Fátima (2009) Uma história de violencia política. Portugal de 1834 a 1851, Lisboa, Tribuna.

Burdiel, Isabel y Romeo, Ma Cruz, (2001): "Viejo y nuevo liberalismo en el proceso revolucionario, 1808-1844", en Preston, Paul y Saz, Ismael (eds.), De la revolución liberal a la democracia parlamentaria, Valencia (1808-1975), Madrid, Biblioteca Nueva-Universidad de Valencia.

Burdiel, Isabel, (2010): Isabel II. Una biografía, Madrid Taurus.

Capellán de Miguel, Gonzalo y Gómez Ochoa, Fidel, (2003): El marqués de Orovio y el conservadurismo liberal español del siglo XIX. Una biografía política, Logroño, Instituto de Estudios Riojanos.

Carnota, Conde de (1880): Memoirs of field-marshall the duke de Saldanha, with selections from his correspondence, Londres, John Murray. 
Chato Gonzalo, Ignacio (2004a) Las relaciones entre España y Portugal a través de la diplomacia (1846-1910), 2 vols., Mérida, Gabinete de Iniciativas Transfronterizas-Junta de Extremadura.

Chato Gonzalo, Ignacio (2004b) "El liberalismo en España y Portugal (1846-1854): paralelismos y divergencias", comunicación presentada al Congreso Internacional Sagasta y el liberalismo europeo, Fundación Práxedes Mateo Sagasta, celebrado en Logroño del 2 al 4 de septiembre.

Chato Gonzalo, Ignacio (2007) "Portugal e Espanha em 1856: a dispar evoluçâo política do liberalismo peninsular", Lisboa, Analise Sócial (Revista do Instituto de Ciências Sociais da Universidad de Lisboa) no 182.

Chato Gonzalo, Ignacio (2008) “La modernización política del liberalismo peninsular (1854-1856): el Bienio progresista y la Regeneraçâo portuguesa", Madrid, Revista de Estudios Políticos no. 139, Centro de Estudios Políticos y Constitucionales.

Chato Gonzalo, Ignacio (2009a) "Las divergentes vías de la conciliación liberal (1856-1861): El Portugal de la Regeneraçâo y la España de la Unión Liberal", Madrid, Historia y Política, no 22.

Chato Gonzalo, Ignacio (2009b) “España ante el nacimiento de la Regeneração: la tentativa de una intervención militar (abril-julio de 1851)", População e Sociedade, no 17, Centro de Estudos da População e Sociedade (CEPESE), Oporto, Universidad de Oporto.

Chato Gonzalo, Ignacio (2010) "La estrategia de la conciliación y el estado liberal, Portugal y España (1858-1863)", Madrid, Espacio, tiempo y forma, no 22, UNED.

Chato Gonzalo, Ignacio (2011a) “La unión liberal y la renovación del sistema de partidos (1858-1863), Madrid, Revista de Estudios Políticos, Centro de Estudios Políticos y Constitucionales (en prensa).

Chato Gonzalo, Ignacio (2011b) “Españoles en Portugal: exilio, emigración y masonería (1843-1868)", en FERRER BENIMELI, José Antonio (coord.), La masonería española. Represión y exilios, actas del XII Symposium internacional de historia de la masonería española, (en prensa).

Chato Gonzalo, Ignacio (2011c) "El fracaso del proyecto regenerador de la unión liberal (1860-1863): el fin de las expectativas de cambio", Cuadernos de Historia Contemporánea, no 33, Universidad Complutense de Madrid, Madrid, 2011, págs. 141-161.
Doria, Luís, (2004): Correntes do radicalismo oitocentista. O caso dos Penicheiros (1867-1872), Lisboa, Imprensa de Ciências Sociais

Durán de la Rúa, Nelson, (1979): La unión liberal y la modernización de la España isabelina. Una convivencia frustrada, 1854-1868, Madrid, Akal.

Eiras Roel, Antonio, (1961): El partido demócrata español (1849-1868), Madrid, Rialp.

Espinha da Silveira, Luís Nuno y Fernandes, Paulo Jorge (2006), D. Luís, Rio de Mouro, Círculo de Leitores.

Estevão, José (1962): Obra política I. Escritos, debates parlamentares e outros discursos. Estudio introductorio, selcción y notas de José Tengarrinha, Lisboa, Portugália Editora.

Freitas Oliveira, Jacintho Augusto de, (1863): José Estevão. Esboço histórico, Lisboa, Sociedade Typographica FrancoPortugueza.

Garrido Muro, Luis, (2002): “El fin del arca de la alianza: alternancia y exclusivismo durante el reinado de Isabel II", en Malamud, Carlos y Dardé, Carlos (eds.), Violencia y legitimidad política y revoluciones en España y América Latina, 1840-1910, Santander, Universidad de Cantabria.

Gil Novales, Alberto, (2001): “Una interminable guerra civil", en Idem (ed.), La revolución liberal, Madrid, Ediciones del Orto.

Gimarães da Cunha, Carlos, (2003): A "Janeirinha" e o partido reformista. Da Revolução de Janeiro de 1868 ao Pacto da Granja, Lisboa Edições Colibrí.

Martínez Gallego, Francesc A., (2001): Conservar progresando: La Unión Liberal (1856-1868), Valencia, Centro Francisco Tomás y Valiente UNED Alzira-Valencia.

Martins, Oliveira, (1996-10ạ edición): Portugal conemporáneo, Lisboa, Guimarâes Editores.

Medina Muñoz, Miguel Ángel, (1975): "La reforma constitucional de 1845", Madrid, Revista de Estudios Políticos, no 203, Centro de Estudios Políticos y Constitucionales,

Millán García, José Ramón, (2001): Sagasta o el arte de hacer política, Madrid, Biblioteca Nueva.

Miraflores, Marqués de, (1964): Memorias del reinado de Isabel II, Ed. Atlas, Madrid.

Olivar Bertrand, Rafael, (1975): Prim, Madrid, Tebas.

Oliveira Marques, A. H. (1996): História da Maçonaria em Portugal. Política e
Maçonaria 1820-1869, Lisboa, Editorial Presença.

Ollero Vallés, José Luis (2006): Sagasta, de conspirador a gobernante, Madrid, Marcial Pons-Fundación Sagasta.

Palacio Cerezales, Diego (2008): Estado, régimen y orden público en el Portugal contemporáneo, (Memoria para optar al grado de doctor), Madrid, Universidad Complutense de Madrid.

Peyrou, Florencia, (2008): Tribunos del pueblo. Demócratas y republicanos durante el reinado de Isabel II, Madrid, Centro de Estudios Políticos y Constitucionales.

Ramos, Rui, (1992): “A formação da inteIligentsia portuguesa (1860-1880)", Lisboa, Análise Social, no 116-117, Instituto de Ciéncias Sociais.

Romeo Mateo, M.a Cruz (2003) "Los mundos posibles del liberalismo progresista", en LA PARRA, Emilio y RAMíREZ, Germán (eds.), El primer liberalismo: España y Europa, una perspectiva comparada, Valencia, Biblioteca Valenciana.

Romeo Mateo, M.a Cruz (2006) "La tradición progresista, historia revolucionaria, historia nacional», en Suárez Cortina, Manuel (ed.), La redención del pueblo. La cultura progresista en la España liberal, Santander, Universidad de Cantabria.

Romeo Mateo, M.a Cruz (2007) "Memoria y política en el liberalismo progresista", Madrid, Historia y Política, núm. 17, Centro de Estudios Políticos y Constitucionales.

Sardica, José Miguel (2001) A Regeneraçâo sob o signo do Consenso: a política e os partidos entre 1851 e 1861, Lisboa, Imprensa de Ciéncias Sociais.

Sardica, José Miguel (2002) “La regeneración en la política portuguesa del siglo XIX", Madrid, Historia y Política, no 7, Centro de Estudios Políticos y Constitucionales.

Sardica, José Miguel (2004) Duque de Ávila e Bolama. Biografia, Lisboa, Publicações Dom Quixote.

Tavares de Almeida, Pedro, (1991): Eleições e caciquismo no Portugal oitocentista (1868-1890), Lisboa, Difel.

Valente, Vasco Pulido, (2002): Glória. Biografia de J. C. Vieira de Castro, Lisboa, Gótica.

Vieira de Castro, J. C. (1866): Discursos parlamentares (1865-1866), Lisboa, Typographia da Gazeta de Portugal.

Vilches, Jorge (2001): Progreso y libertad. EI partido progresista en la revolución liberal española, Madrid, Alianza Editorial. 